\title{
ANTÓN ALONSO RÍOS (1887-1980): EMIGRACIÓN, FILANTROPÍA, REPUBLICANISMO, REPRESIÓN Y EXILIO DE UN MAESTRO RURAL
}

\author{
Antón Alonso Ríos (1887-1980): Emigration, philanthropy, \\ republicanism, repression and exile of a rural teacher
}

\section{Xosé Manuel Malheiro Gutiérrez ${ }^{\&}$}

Fecha de recepción: 20/04/2018 • Fecha de aceptación: 15/06/2018

Resumen. El presente texto reconstruye el perfil biográfico de un profesor gallego y líder político, Antón Alonso Ríos, teniendo en cuenta cinco aspectos que señalan, a su vez, sucesivas etapas en su trayectoria vital: la primera, como emigrante en la Argentina, marcada por su liderazgo entre una parte importante de la diáspora gallega; la segunda, durante la República Española (1931-1936), etapa definida por su actividad política en Galicia con vinculaciones a la causa nacionalista y al movimiento agrarista; la tercera, su experiencia como "huido», consecuencia de la represión fascista a la que fue sometido durante la guerra civil; por último, el destierro en Buenos Aires hasta su muerte, dando presencia y continuidad al gobierno gallego en el exilio con el Consello de Galiza. Para ello se ha revisado diversa bibliografía relacionada con la emigración gallega a América y con la represión franquista en Galicia; se ha consultado prensa periódica gallega y americana de la época; se han revisado los fondos del Archivo provincial de la Diputación de Pontevedra, del Arquivo da Emigración del Consello da Cultura Galega (Santiago de Compostela) y se ha consultado diversa documentación societaria ubicada en archivos personales.

Palabras clave: Emigración gallega; Sociedades de instrucción; Antón Alonso Ríos; Represión franquista; Magisterio gallego.

Abstract. The present text reconstructs the biographical profile of a Galician teacher and political leader, Antón Alonso Rios, focusing on five aspects which mark consecutive stages in his vital trajectory: the first, as an emigrant in Argentina, marked by his leadership among an important part of the

\footnotetext{
\& Dpto. de Pedagoxía e Didáctica, Facultade de Ciencias da Educación, Universidade da Coruña. Elviña, s.n., 17051 A Coruña. España. jose.malheirog@udc.gal
}

Cómo citar este artículo: Malheiro Gutiérrez, Xosé Manuel. «Antón Alonso Ríos (1887-1980): Emigración, filantropía, republicanismo, represión y exilio de un maestro rural». Historia y Memoria de la Educación 9 (2019): 473-520. 
Galician diaspora; the second, during the Spanish Republic (1931-1936), a stage defined by his political activity in Galicia with connections to the nationalist cause and the agrarian reform; the third, his experience as a "fugitive» as a consequence of the fascist repression to which he was subjected during the Civil War, and lastly, his banishment in Buenos Aires - until his death - where he provided presence and continuity to the Galician government in exile with the Consello de Galiza (Council of Galicia). We have consulted the myriad, diverse bibliography involving Galician emigration to America and the Francoist repression, including Galician and American press from the time;; the collection of the provincial Archive of the Diputación de Pontevedra (Council of Pontevedra); the Arquivo da Emigración (Emigration Archive) from the Consello da Cultura Gallega (Galician Culture Council) (Santiago de Compostela) and diverse corporate documentation from personal documents.

Keywords: Galician emigration; Societies of education; Antón Alonso Ríos; Francoist repression; Galician teaching.

\section{DE GALICIA A LA ARGENTINA}

Para llegar a entender en toda su complejidad a un personaje como Antón Alonso Ríos (Silleda, Pontevedra 1887-Buenos Aires, 1980), es necesario observar cinco aspectos que señalan, a su vez, sucesivas etapas en su trayectoria vital: la emigración y la filantropía ligada al asociacionismo emigrante, la política republicana, su experiencia como fuxido, y el destierro en Buenos Aires, hasta su muerte. ${ }^{1}$ Emigración, filantropía, política, represión y exilio se funden en la globalidad de su pensamiento marcado por una honda preocupación pedagógica, que parte de su admiración por Francisco Giner de los Ríos en un plano intelectual más teórico, y se modela progresivamente con aportes que provienen de su práctica docente, primero en la escuela argentina (1909-1920) y más tarde en Galicia (1931-1936). De todo ello resulta un discurso integrador, donde confluyen vivencias profesionales de ambos entornos escolares, tan diferenciados como lo eran el argentino y el gallego a comienzos del siglo xx.

\footnotetext{
${ }^{1}$ Que hemos tratado parcialmente en trabajos anteriores: «Antón Alonso Ríos: unhas notas sobre emigración, agrarismo e vida rural», A Trabe de Ouro. Publicación galega de pensamento crítico 53 (2003): 81-85; «Antón Alonso Ríos: política e pedagoxía para un pobo», en VV.AA., Homenaxe a Antón Alonso Ríos e Ramón de Valenzuela (Santiago de Compostela: Xunta de Galicia, 2006), 101-110.
} 


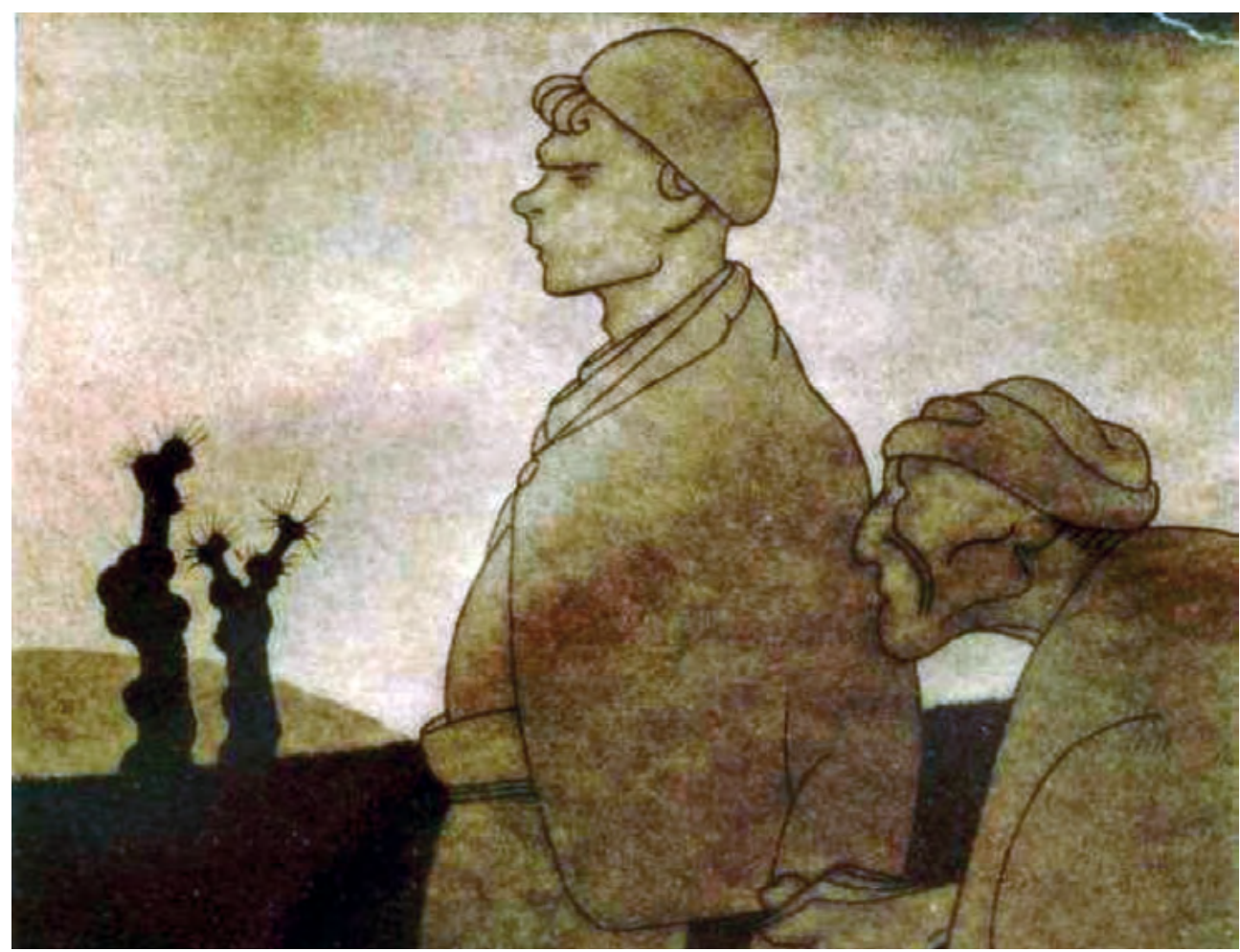

Imagen 1. Castelao retrata el drama de la emigración, que llega a nuestros días: «¿Para qué quieres irte de la Tierra? ¿No tenemos pan en el horno?»

Fuente: Álbum Nós. Lámina 8. Hauser y Menet, Madrid 1931. Real Academia Galega de Belas Artes.

Antón Hipólito Alonso Ríos nace el 15 de agosto de 1887 en el seno de una modesta y numerosa familia de comerciantes rurales establecida en los alrededores de Silleda (Pontevedra). ${ }^{2}$ En la escuela parroquial aprendió los rudimentos básicos que poco más tarde ampliará en la escuela primaria. En 1903, con dieciséis años, inicia sus estudios de magisterio en Compostela logrando superar todas las materias en tres cursos y hacerse profesor auxiliar. Pero una enfermedad trunca la carrera del joven profesor, que regresa a Silleda y se incorpora a la actividad comercial familiar. Insatisfecho con la nueva vida e inquieto en la búsqueda de nuevos caminos decide, como tantos jóvenes en la Galicia

${ }^{2}$ Para conocer detalles más concretos de su biografía puede consultarse, entre otras fuentes: Bieito Alonso Fernández, Antón Alonso Ríos: Crónica dunha fidelidade (Santiago de Compostela: Edicións Laiovento, 1996). 
de su tiempo, dar el salto a la emigración. Con el dinero y una carta de recomendación que le proporciona una amistad ${ }^{3}$ embarca en el puerto de Vigo rumbo a Buenos Aires donde, como era frecuente en el entorno migratorio, le esperaba el cobijo de un conocido y la orientación necesaria en sus primeros pasos lejos de Galicia.

Su formación inicial como maestro le garantiza un rápido acomodo en el nuevo destino al poder validar su título en el Consejo Nacional de Educación, y a las pocas semanas estaba ya trabajando en una escuelita de la capital. ${ }^{4}$ Como es sabido, desde la independencia, y con mayor intensidad con el cambio de siglo, había en la Argentina gran demanda de cuadros técnicos, por lo que los inmigrantes cualificados eran los mejor recibidos: «Cada europeo que viene, nos trae más civilización en sus hábitos que el mejor libro de filosofía», afirmaba Juan Bautista Alberdi finalizando el siglo XIX. ${ }^{5}$ Una acogida especialmente positiva en el caso de los docentes, pues entre las prioridades del Estado emergente estaba la de educar "argentinamente» ${ }^{6}$ aquella masa inmigrante tan heterogénea. Y el mejor instrumento era la escuela primaria, para lo cual se necesitaban muchos maestros.

Esta primera experiencia laboral le da acceso al mundo de la enseñanza y su posición le permite observar desde una óptica privilegiada la efervescencia reivindicativa de la sociedad civil argentina, un crisol que fundía masas de obreros con lenguas diversas, distintas culturas y dispares grados de formación y de cualificación profesional. Era la rea-

\footnotetext{
${ }^{3}$ Victoria Armesto, Los Hijos cautivos de Breogán. El rastro de Castelao en América (Sada-A Coruña: Ediciós do Castro, 1986), 62.

${ }^{4}$ Xosé María Álvarez Blázquez, «Prólogo», en O Siñor Afranio. Ou como me rispei das gadoupas da morte, ed. Antón Alonso Ríos, (Vigo: Edicións Castrelos,1979), 12.

5 Juan Bautista Alberdi, Obras completas (Buenos Aires: Imprenta de «La Tribuna Nacional», 1886), t. III, 88.

${ }^{6}$ Refiriéndose a las escuelas creadas por los inmigrantes italianos, Faustino Domingo Sarmiento escribía en 1881: «Qué es eso, pues, de educar italianamente? Lo que se consigue es que nunca sepan la lengua del país [...]. En simpatías por la Italia libre, artística y unificada, no nos ha de ganar ningún napolitano, piamontés, romano o genovés de los que viven entre nosotros. Es necesaria una escuela común donde los niños no se eduquen italianamente, sino argentinamente». Valeria Sardi, Historia de la enseñanza de la lengua y la literatura. Continuidades y rupturas (Buenos Aires: Libros del Zorzal, 2006), 66. Sobre esta cuestión, Adriana Puigróss indica que, para Sarmiento, «educar "argentinamente" era [...] ir en pos de un modelo universal educando como Horace Mann, o como Pestalozzi»: Sujetos, disciplina y curriculum en los origenes del sistema educativo argentino (18851916) (Buenos Aires: Editorial Galerna, 2006), 103.
} 
lidad social de miles de proletarios que en su inmensa mayoría habían cambiado de país pero no de situación, debiendo someterse a unas duras condiciones laborales y adaptarse a nuevos códigos culturales, reglas sociales, legislación e incluso idioma; y tomar conciencia de los límites existentes entre la utopía imaginada y la realidad presentada, al constatar una doble opresión: como asalariados y como extranjeros. ${ }^{7}$ Esa era también una realidad observada y padecida por la inmensa mayoría de sus compatriotas gallegos y que él, afortunadamente, no llegó a conocer en términos tan duros gracias al nivel de formación y de cualificación profesional con el que había llegado a Buenos Aires.

Allí comprueba cómo la devoción por la escuela que sentían los poderes públicos en la Argentina finisecular contrastaba con el abandono y la desidia conocida de modo vivencial en Galicia. La cuestión educativa, observaba en 1930, "no es un problema de estómago, ni de protección a nadie; es el problema único, el problema substancial que ha de resolver toda nación que no quiera quedarse indefinidamente a la zaga de los pueblos cultos constituyendo una rémora vergonzosa para el progreso general de la humanidad». ${ }^{8}$ Esto le permite analizar las causas, confirmar las deficiencias y descubrir aspectos organizativos que, siendo en aquel momento objeto de un intenso debate pedagógico, acaba incorporando a su concepto de escuela rural. Por ejemplo, las ventajas de graduar los niveles de enseñanza; la importancia de articular una inspección útil y efectiva; la urgente necesidad de dignificar el trabajo de los maestros, condenados al crónico aislamiento y al abandono administrativo; la conveniencia de adaptar las escuelas al contexto gallego, incorporando un currículum específico en la lengua materna, con horario y calendario «conciliadores» —en expresión actual—con el ciclo productivo agrícola; la obligación de implantar criterios pedagógicos funcionales en el diseño arquitectónico de los edificios escolares; o,

\footnotetext{
7 Julio Godio, El nacimiento de la clase obrera argentina (Buenos Aires: Editorial Legasa, 1987). También, Xosé Manuel Nuñez Seixas, O inmigrante imaxinario. Estereotipos, representacións e identidades dos galegos na Arxentina (1880-1940) (Santiago de Compostela: Universidade de Santiago de Compostela, 2002); Iaacov Oved, El anarquismo y el movimiento obrero en Argentina (Buenos Aires: Siglo XXI, 1978); Xosé Manuel Malheiro Gutiérrez, «Do "gobernar es poblar” ao "educar es argentinizar": Emigrantes e educación na Arxentina finisecular», Sarmiento. Anuario Galego de Historia da Educación 17 (2013): 161-84.

8 Antón Alonso Ríos, «Sobre educación agraria», El Despertar Gallego 163 (1930): 4.
} 
en fin, la necesidad de prestar atención solidaria a la formación de adultos mediante programas de alfabetización.

De aquel puesto en la escuela urbana pasa a otra rural, la $n .^{\circ} 32$ «Arroyito», en el Departamento de La Paz (Mendoza). ${ }^{9}$ Posteriormente regresa a Buenos Aires, donde se matricula en la Facultad de Filosofía y Letras e ingresa como profesor en el «Víctor Hugo», un colegio privado de cierto prestigio, y allí permanece hasta 1913. También por aquellos años, entre la colectividad, conoce a Oliva Rodríguez, con la que contrae matrimonio en 1914, del que nacen cuatro hijos: Oliva, Chamor, Ombú y Celta. Desde ese año y hasta 1920 ejerce como profesor de Historia en el Instituto Politécnico de la capital. Luego abandona temporalmente la docencia y acepta otros empleos hasta que en 1931 regresa a Galicia.

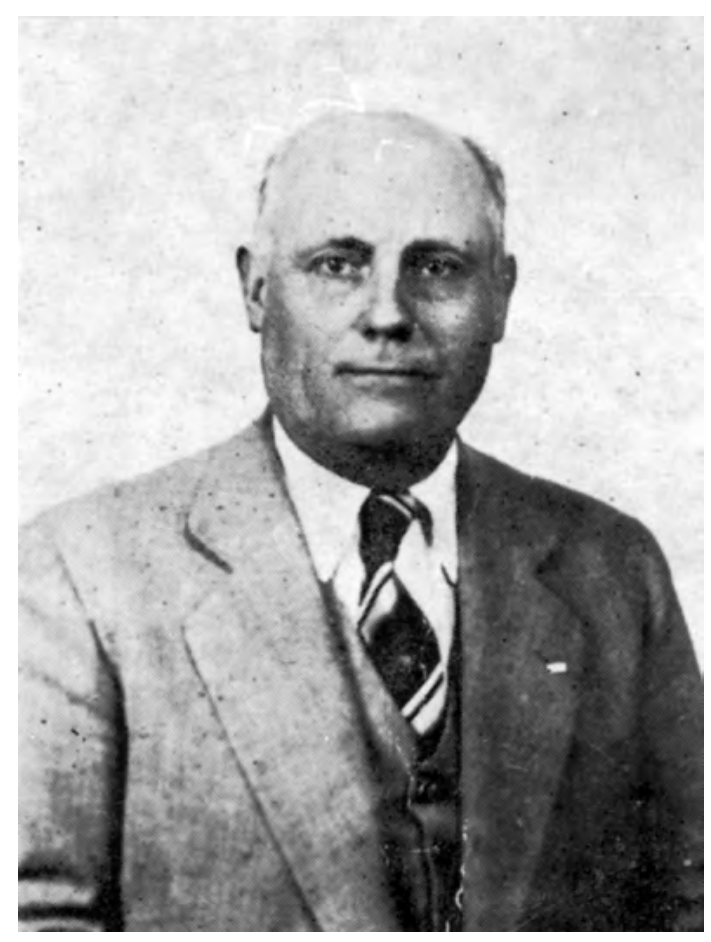

Imagen 2. Antón Alonso Ríos, años 30

\footnotetext{
${ }_{9}^{9}$ Consejo Nacional de Educación, Actas de las Sesiones del Consejo Nacional de Educación (Buenos Aires: Consejo Nacional de Educación, 1908), t. I, 155 (Información que debo a la amabilidad de Diego Adrián Clemenz Alonso, nieto de Antón Alonso Ríos).
} 


\section{EMIGRACIÓN Y ASOCIACIONISMO: LA SOCIEDAD DE INSTRUCCIÓN HIJOS DE SILLEDA}

Si existe un rasgo común entre las comunidades migrantes que trasciende al origen geográfico, al contexto sociocultural o al momento histórico, es la búsqueda de vínculos emocionales que ayuden a superar el dilema entre la resistencia a abandonar los valores de la sociedad de origen y las dificultades para adaptarse a las nuevas reglas marcadas por la sociedad de destino. Eso hizo que los miembros de dichas comunidades se fuesen nucleando en torno a asociaciones de carácter étnico, entre cuyos objetivos estaban la alfabetización urgente, la protección de la cultura originaria y del idioma además de, en muchos casos, la satisfacción de otras necesidades no suficientemente atendidas como la salud, el empleo o la repatriación. ${ }^{10}$

La diáspora gallega, con una presencia muy fuerte en la Argentina, el Uruguay y la isla de Cuba no es ajena a ese patrón, y así levanta en 1879 los Centros Gallegos de Buenos Aires, Montevideo y La Habana, tres grandes instituciones mutualistas a las que seguirán posteriormente, a lo largo del primer tercio del siglo xx, varios centenares de sociedades de ámbito parroquial, ${ }^{11}$ municipal y comarcal, movidas por vínculos territoriales, culturales o afectivos, con el objeto de preservar la identidad colectiva original en el nuevo destino o prestar algún tipo de auxilio mutualista. ${ }^{12}$

Como se ha puesto de manifiesto también en diferentes estudios, las comunidades migrantes del sur de Europa comparten una percep-

\footnotetext{
${ }^{10}$ Siguiendo este patrón, mediada la centuria nacieron las primeras asociaciones de ayuda mutua de ámbito nacional en Buenos Aires y otros núcleos urbanos, como la Asociación Francesa (1854), Unión e Benevolenza italiana (1858), la Sociedad Española de Socorros Mutuos (1875), Sociedad Polaca de la República Argentina (1890), Asociación Patriótica Española (1896), Sociedad de Socorros Mutuos y de Ayuda Social Árabe Musulmana de Córdoba, en 1928, o el Centro Islámico Argentino, creado por esos años. Hacia 1890 existían en la capital más de 70 asociaciones de este tipo y alrededor de 150 en todo el país.

${ }^{11}$ En los municipios rurales de Galicia existe la «parroquia» como demarcación local, aunque carece de reconocimiento legal expreso. Cada ayuntamiento está compuesto por un número de parroquias. Sobre este tema, pueden consultarse: Xosé Fariña Jamardo, La parroquia rural en Galicia (Madrid: Instituto de Estudios de Administración Local, 1975).

12 Xosé Manoel Nuñez Seixas, «A parroquia de Alén Mar: Algunhas notas sobre o asociacionismo local galego en Buenos Aires (1904-1936)», Semata. Ciencias Sociais e Humanidades 11 (1999): 345-79.
} 
ción positiva sobre la escuela y sus efectos, como lo demuestra su intervención alfabetizadora en el lugar de destino ${ }^{13}$ o en el de origen a través de proyectos filantrópicos particulares. ${ }^{14}$ Pero en el caso gallego, además de la iniciativa individual, enmarcada en la órbita tradicional caritativa, se llevó a cabo durante el primer tercio del siglo xx una intervención en el ámbito de lo que entendemos como educación popular y fuertes connotaciones de solidaridad comunitaria, a través de las denominadas «sociedades de instrucción». ${ }^{15}$ Muchas de estas sociedades -y aquí radica su originalidad - nacían para satisfacer la necesidad sentida de alfabetización entre las clases populares campesinas y marineras, situadas en aquel momento en clara desventaja de oportunidades frente a las que residían en núcleos urbanos, como punto de arranque para la regeneración democrática de la sociedad gallega y para la mejora de sus condiciones de vida. En el primer tercio del siglo xx, se fundaron alrededor de 500 sociedades; una parte de ellas no llegó a alcanzar los objetivos previstos en su creación, pero la mayoría llevó a cabo

\footnotetext{
13 Para el caso gallego: Narciso de Gabriel, «Emigración y alfabetización en Galicia», Historia de la educación. Revista interuniversitaria 4 (1985): 330, y más recientemente: «A emigración como factor dinamizador da alfabetización», en Actas do Congreso Emigración e Educación (1900-1936). I Centenario das Escolas da Unión Hispano-Americana Valle Miñor (1909-2009), coord. Xosé Manuel Malheiro Gutiérrez (Gondomar: Instituto de Estudos Miñoranos/Consello da Cultura Galega, 2011), 205-227; para el caso portugués: Jorge Fernandes Alves, "Os Brasileiros»: Emigração e Retorno no Porto Oitocentista. (Porto: Faculdade de Letras da UP, 1993); para el caso italiano: Alberto Barausse, "Nationalisms and schooling: between italianity and brazility, disputes in the education of italian-gaucho people (Rs, Brazil, 1930-1945)», History of Education \& Children's Literature XII, no. 2 (2017): 443-75.
}

14 Para el caso de España, consúltese Antonio Viñao Frago, «Filantropía y educación. Fundaciones docentes y enseñanza elemental (siglos XVIII-XIX)», en L'enseignement primaire en Espagne et en Amérique Latine du XVIII siècle à nos jours, dirs. Jean-René Aymes, Ève-Marie Fell y Jean-Louis Guereña (Tours: Université de Tours, 1986), 65-79; referido a Galicia: Antón Costa Rico, «Emigrantes, escuelas y regeneración social: los emigrantes gallegos a América y el impulso de la educación (1879-1936)», Revista Brasileira da Educaçao 16 (2008): 33, y Vicente Peña Saavedra, «Panorámica de la intervención escolar de los emigrantes gallegos a América (siglos XVII-XXI)», en El asociacionismo y la promoción escolar de los emigrantes del Norte Peninsular a América, coords. Moisés Llordén Miñambres y José Manuel Prieto Fernández del Viso (Boal: Ayuntamiento de Boal, 2012), 35-69. La filantropía particular ligada a la escolarización primaria es un fenómeno que también se observa en Portugal, donde destaca el Conde de Ferreira, que a su muerte dejó un legado para construir 120 escuelas. Véase la biografía elaborada por Fernandes Alves, «Percursos de um brasileiro no Porto: o Conde de Ferreira», Revista da Faculdade de Letras. História 9 (1992): 199-214.

${ }^{15}$ La primera de estas sociedades es la Alianza Aresana de Instrucción, fundada en La Habana en 1904, que construyó su primer edificio escolar en 1908. Ese mismo año nace en Buenos Aires La Concordia, sociedad de ámbito parroquial, formada por los naturales de Fornelos da Ribeira (Salvaterra), que en 1906 ya colaboraba al sostenimiento del colegio público de Fornelos. 
diferentes obras de carácter sociocultural, llegando a crear unos 150 colegios y casi 500 aulas primarias en diferentes puntos de Galicia, ${ }^{16}$ conocidas popularmente como "escuelas laicas»o "escuelas de emigrante», que con alguna frecuencia tenían su inspiración en los modelos que en esos momentos desarrolla — dicho genéricamente- la vanguardia pedagógica argentina. ${ }^{17}$ Algunas de las sociedades, incluso, nacen exclusivamente para crear escuelas y promocionar la enseñanza primaria a través de una instrucción adaptada al entorno rural. Fue un fenómeno singular de la emigración gallega, no observado en otras comunidades europeas o asiáticas que, también por aquel tiempo, se establecieron masivamente en América.

Crear escuelas en Galicia desde la emigración era, para Alonso Ríos, «la obra más acertada, de más inmediatos resultados y de mayor proyección hacia el futuro de Galicia en términos de regeneración social y desarrollo económico", ${ }^{18}$ como expresaba en 1929 en El Despertar Gallego. En su opinión, cada escuela creada por la comunidad emigrante, además de instrumento eficaz de difusión cultural y de capacitación para la vida social, debía ser semilla de conciencia colectiva: «una escuela con carácter y orientación definidos, de tal suerte que pudiera servir de base a un movimiento social emancipador, a un movimiento de liberación y de resurgimiento económicos». ${ }^{19}$

Sin embargo, el asociacionismo ligado a la instrucción, en el que directa o indirectamente participaron miles de gallegos y gallegas, no se habría desarrollado del modo que hoy conocemos de no ser por la presencia activa de un grupo de intelectuales y de su papel como minoría llamada a concienciar y difundir las ideas sobre las que se asentó la intervención solidaria. Y el número de establecimientos escolares de enseñanza primaria en Galicia, complementarios a los oficiales,

\footnotetext{
16 Costa, «Emigrantes, escuelas y regeneración social», 13.

17 Xosé Manuel Malheiro Gutiérrez, «Una nueva luz. La influencia de la escuela argentina en la intervención de los emigrantes gallegos en sus lugares de origen", Historia de la Educación. Revista interuniversitaria 26 (2007): 341-66.

18 Antón Alonso Ríos, «Educación agraria. Las escuelas creadas por las asociaciones de emigrados», El Despertar Gallego 159 (1929): 5.

19 Antón Alonso Ríos, «Nuestra Federación y el renacimiento nacionalista gallego. Dos manifestaciones del mismo sentimiento», El Despertar Gallego 89 (1926): 5.
} 
no habría prosperado sin el apoyo de esa minoría de emigrados ${ }^{20}$ que compartían con los primeros la procedencia geográfica, su condición de migrantes y el conocimiento sobre las necesidades materiales del lugar de partida, pero que poseían además la determinación necesaria para impulsar las diferentes iniciativas que habrían de satisfacer esas necesidades. ${ }^{21}$

Antón Alonso Ríos era, en ese sentido, un emigrante más en busca de vínculos y afectos entre los coterráneos. Además, por su formación y su posición, pertenecía a esta élite intelectual que dinamizaba y estimulaba al resto de la comunidad con ideas e iniciativas de carácter identitario y una definida orientación política. Y en ese sentido, pudo observar con cierta frustración cómo una parte de la colectividad gallega, con escasa memoria sobre los problemas que Galicia padecía, se dedicaba

al fomento del tango y del tresillo, y las únicas intromisiones que tenían en la vida de su patria, consistían en enviar docenas de telegramas destinados a El Rey, absurdo e indiferente, o a los jefes de los gobiernos que fomentaban el caciquismo, que consentían la despoblación - por hambre- de Galicia y que sellaban, a balazo limpio, las bocas que pedían pan y libertad. $^{22}$

Ese compromiso político y social le llevará a liderar la fundación de la sociedad Hijos de Silleda, en 1908; y la de la Federación de Sociedades Gallegas, Agrarias y Culturales, en 1921. La sociedad de instrucción denominada Hijos de Silleda nacía el 15 de agosto de 1908 con una clara identidad de orientación republicana. ${ }^{23}$ Sus objetivos: "crear y fomentar escuelas, proteger a sus asociados, cultivar y difundir el espíritu de asociación, establecer relaciones con las sociedades que se propongan

\footnotetext{
${ }^{20}$ Hablamos, en particular, de gentes ligadas a la masonería, al republicanismo y al federalismo que al final de la Primera República española (1874) sintieron la necesidad de buscar horizontes con mayor libertad política e ideológica.

${ }^{21}$ Alberto Vilanova Rodríguez, Los gallegos en la Argentina (Buenos Aires: Ediciones Galicia, 1966), 2 vols.

22 «Sobre la Federación de Sociedades Gallegas, Agrarias y Culturales», Céltiga 24 (1925): s.p.

${ }^{23}$ El socio fundador Antonio Carballo destacaba en 1943 el trabajo societario realizado "para desterrar la Monarquía, con todo su bagaje de parásitos que jamás hicieron nada por el pueblo como no fuera vejarlo y esquilmarlo». Galicia 848 (1943): 3.
} 
la difusión de la enseñanza laica o la ayuda al pueblo productor gallego pudiendo federarse con ellas, y fomentar el acercamiento hispano-argentino». ${ }^{24}$ Antón Alonso Ríos participa activamente influyendo de modo determinante en su orientación educativa ${ }^{25}$ y tratando de conciliar a los que defendían una intervención centrada en «el estímulo a los labriegos en el sentido de que mejoraran en lo posible sus productos agropecuarios» mediante colaboración con la Sociedad de Agricultores de Silleda; ${ }^{26}$ y a los que optaban por la promoción de la enseñanza explícitamente laica, denunciando «el estado lamentable en que se encuentra la Instrucción Primaria en toda Galicia, pero muy particularmente entre la población rural, la que cuenta con un porcentaje de analfabetos de más de $50 \%$, adoleciendo el 50\% restante, en su casi totalidad, de educación e instrucción deficientes, por ser dirigidas de una manera rutinaria y extraña a los principios de la pedagogía moderna». ${ }^{27}$ La Sociedad Hijos de Silleda intervino en la creación de tres centros escolares con edificios propios y sostuvo dos más en locales alquilados. La escuela «Rosalía de Castro» empieza a funcionar en 1912, ${ }^{28}$ la «Bernardino Rivadavia», en $1917^{29}$ y la

\footnotetext{
${ }^{24}$ Sociedad Hijos de Silleda. Acta De Fundación (Buenos Aires, 15 de agosto de 1908), 1.

${ }_{25}$ «Entrevista con el Federado Antonio Carballo, Fundador de la Sociedad de Silleda», Galicia 848 (1943): 3.

${ }^{26}$ Sociedad Hijos de Silleda. Libro de Actas (Buenos Aires, 15 de agosto de 1909), 5; si se observa, el artículo 21 del Reglamento de la Sociedad de Agricultores del Ayuntamiento de Silleda dicta: «Podrá la Sociedad, más adelante, cuando su desarrollo lo permita, como es de esperar, y los emigrados hijos de Silleda residentes en América, cooperen a su protección, emprender otras empresas como adquisición de un domicilio social propio, creación de centros de enseñanza, de cajas de ahorro y préstamo, Sociedad de seguros de ganados y cosechas, etc., etc., lo que redundará en beneficio de los socios y del país en general», Ver: Sociedad de Agricultores del Ayuntamiento de Silleda, Reglamento (Santiago de Compostela: Tipografía del Eco de Santiago, 1909$), 7$.

${ }^{27}$ Sociedad Hijos de Silleda. La Sociedad «Hijos de Silleda» a los Miembros de las Asociaciones similares. Biblioteca América de la Universidad de Santiago (documento suelto, sin paginar).

${ }^{28}$ Una nota en Suevia 2 (1913): 2, informaba: «viene funcionando admirablemente, bajo la dirección de un distinguido pedagogo compostelano. En la actualidad hay matriculados unos ochenta niños, los que reciben una esmerada educación, lo cual dice mucho a favor de tan filantrópica asociación, porque demuestra que la enseñanza de las primeras letras en aquella comarca, era de imperiosa necesidad».

${ }^{29}$ En la Asamblea ordinaria celebrada el 13 de octubre de 1918, Alonso Ríos solicita una subvención de 150 pesos para mobiliario y útiles escolares de esa escuela, situada en la parroquia de Penadauga, así como aumento de salario para el maestro de la de Freixeiro, que la propia Asamblea fija en «25 duros españoles» por mes. Sociedad Hijos de Silleda. Libro de Actas (Buenos Aires, 13 de octubre de 1918), 76.
} 
«Francisco Giner de los Ríos», en $1921 .{ }^{30}$ Las tres representan una esclarecedora simbología: Rosalía de Castro encarna la afirmación galleguista del proyecto societario; Bernardino Rivadavia, señala una profunda convicción democrática identificada con el primer presidente argentino electo, de ascendencia gallega; Francisco Giner de los Ríos denota una explícita preocupación por la renovación pedagógica y la confianza depositada en la educación como instrumento emancipador. La sociedad sufragaba el funcionamiento de una cuarta de niñas en régimen de alquiler y destinaba una subvención anual de 60 pesos argentinos para mantener un quinto local escolar en una parroquia apartada, pues «se encuentran en aquel punto muchos niños que carecen de la más elemental instrucción, y la sociedad cuenta en la actualidad con recursos suficientes para hacer funcionar la escuela». ${ }^{31}$ Todas ellas supervisadas en su funcionamiento por un inspector escolar. En el año 1929, la sociedad se nutría con las aportaciones de 600 socios entre Buenos Aires y Montevideo, lo que permitía la escolarización de 479 alumnos y alumnas. ${ }^{32}$

Además de socio fundador, Alonso Ríos ocupa diferentes responsabilidades en el organigrama societario. Entre 1910 y 1914 desempeña el puesto de secretario y en 1916 es elegido presidente; en 1927 forma parte de la tesorería y en 1930 participa como delegado de la Sociedad en el VII Congreso de la Federación. Además, preside desde 1914 la Comisión escolar de la Sociedad redactando el Reglamento Oficial, ${ }^{33}$ se encarga de elaborar el programa pedagógico de las escuelas ${ }^{34}$ y organiza el programa de alfabetización de adultos que la entidad ofrece a los socios emigrados. En 1931 embarca a Galicia en comisión para, entre otras tareas,

\footnotetext{
${ }^{30}$ La Sociedad atiende, de este modo, la petición que le formulan 24 vecinos: «Respondiendo al pedido de los vecinos de la parroquia de Siador, se acuerda fundar la escuela $n .{ }^{\circ} 3$, la que deberá establecerse en el lugar de La Portela, quedando fijada la fecha de su inauguración para septiembre de mil novecientos veintiuno». Ver, Sociedad Hijos de Silleda. Libro de Actas (Buenos Aires, 11 de julio de 1920), 109.

${ }^{31}$ Sociedad Hijos de Silleda. Libro de Actas. (Buenos Aires, 4 de febrero de 1917), 68.

32 "Sociedad Hijos de Silleda», Correo de Galicia 1066 (1926): 4.

${ }^{33}$ Sociedad Hijos de Silleda. Libro de Actas (Buenos Aires, 8 de noviembre de 1914), 38.

${ }^{34}$ Encargado de cada escuela «se halla un maestro con título nacional y una comisión escolar local. Un inspector técnico tiene a su cargo la dirección superior de la enseñanza en Galicia, y un asesor técnico ilustra aquí a la C. D. En cuestiones de enseñanza y necesidades escolares», El Despertar Gallego 161 (1929): 6.
} 
gestionar del gobierno de la República Española el reconocimiento oficial de nuestras escuelas, o en su defecto, que éstas sean subvencionadas por el Estado, e iniciar una intensa campaña de propaganda republicana y galleguista para que nuestra región, en esta oportunidad quizá única en la historia, llegue a conquistar la plenitud de sus libertades políticas. ${ }^{35}$

En 1934, la Asamblea le concede el título de Socio de Honor, aceptado por unanimidad.

Su actividad societaria se extiende a otras entidades como la Sociedad Pro Escuelas en Bandeira (Silleda, Pontevedra), la Unión del Partido de Lalín ( Pontevedra), la Asociación Pro Escuela en Moraña (Pontevedra), Nueva Era de Vilanova (Vedra, A Coruña), Unión y Progreso de San Julián de Sales (Vedra, A Coruña); Mutualista y Pro escuelas del Distrito de Caldas (Pontevedra) o la Unión Galaico-Americana (O Pino, A Coruña), que con el tiempo acabarán integradas en una Federación. Todas ellas crearon escuelas en las que se implantaron pautas como la graduación de la enseñanza, la armonización de los horarios escolares con la vida en el mundo rural para evitar el absentismo, la dignificación salarial de los maestros, la aplicación de un sistema común de inspección, la creación de bibliotecas populares y de clases nocturnas para adultos o la introducción de nuevas técnicas agrícolas a través de huertos escolares. Eran, en su conjunto, aspectos innovadores que definían un modelo inédito, hasta ese momento, en el escenario escolar oficial.

\section{FEDERACIÓN DE SOCIEDADES GALLEGAS, AGRARIAS Y CULTURALES: EL IMPULSO «AMERICANO»A LA ESCOLARIZACIÓN PRIMARIA}

Que entre los objetivos de la sociedad Hijos de Silleda se encuentre el de federarse con sociedades similares, tal como ya desde el inicio de los años diez se había pretendido igualmente desde impulsos emprendidos entre la también muy numerosa emigración gallega en la isla de Cuba, responde a la idea de crear una organización que diese uniformidad a la acción desarrollada, de forma incipiente, por estas sociedades. Y lo ex-

\footnotetext{
35 Sociedad Hijos de Silleda: Libro de Actas (Buenos Aires, 17 de mayo de 1931), 219.
} 
presa más adelante, en 1931, en las páginas de Galicia: «La Sociedad Hijos de Silleda comprende que la obra local se halla supeditada a una empresa general; y sin detenerse a calcular fuerzas, se lanza a ella». ${ }^{36}$ Antón Alonso Ríos ya había empezado a trabajar en un ambicioso proyecto de escolarización rural extensible al conjunto del territorio gallego, donde pudieran integrarse todas las sociedades de instrucción y sus escuelas. Del lado americano, una Federación - la sociedad de Silleda era la semilla de ese organismo a partir de 1921 - que sintetizara y unificara los criterios pedagógicos e incluso ideológicos de las entidades adheridas; del lado gallego, una red de escuelas laicas, con un modelo de enseñanza de inspiración institucionista: «basada en la razón que encauza la inteligencia de los niños hacia el gran libro, siempre abierto para quien sabe comprenderlo, que se llama Naturaleza». ${ }^{37}$ Esta red escolar actuaría de modo coordinado con la Federación de sociedades matrices radicadas en América para responder al déficit escolar que, tanto en infraestructuras como en personal y métodos presentaba el sistema educativo en Galicia. En 1927 se preguntaba dónde estaban las escuelas para atender a los 15.000 ciegos y 10.000 sordos que había en España; dónde las 2.500 escuelas auxiliares para acoger a los niños deficientes; dónde las escuelas nocturnas para obreros, como las que existían en otros países de Europa al tiempo que denunciaba: «Faltan escuelas: escuelas primarias en número adecuado a la población [...]. Faltan escuelas nuevas, de planta, en sitios donde nunca las hubo, y falta derruir las tres cuartas partes de los locales que hoy se habilitan para escuelas». ${ }^{38}$ Más adelante volverá sobre este asunto en términos parecidos:

¿Qué demanda nuestra sociedad en el orden educacional? En primer lugar la piqueta. La piqueta que no deje piedra sobre piedra, desde el Ministerio de Instrucción Pública hasta la última escuela rural. La escuela oficial y no oficial, no sólo no cumple una misión formativa de la personalidad del niño, sino que atenta contra esa personalidad, la deforma y envilece, y además conspira contra los designios de nuestra nacionalidad. ${ }^{39}$

\footnotetext{
36 «La Sociedad Hijos de Silleda ha dado un buen paso», Galicia 199 (1931): 1.

37 «Sociedad Hijos de Silleda», El Despertar Gallego 88 (1926): 3; también: Sociedad Hijos de Silleda, Boletín informativo n. 24 (Buenos Aires: Hijos de Silleda, 1983), 1.

38 Antón Alonso Ríos: «Faltan escuelas», El Despertar Gallego 99 (1927): 1.

39 Antón Alonso Ríos: «Dos posiciones del SEG ante el presente», El Pueblo Gallego 3566 (1935): 1.
} 


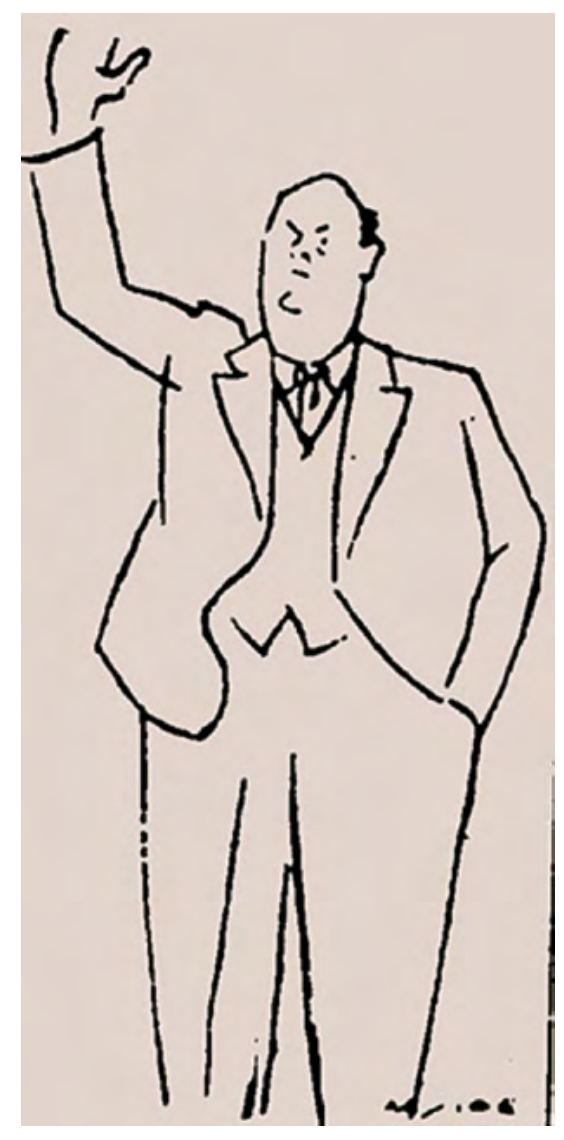

Imagen 3. Alonso Ríos visto por su amigo, el pintor e ilustrador Carlos Maside

Respecto a las ideas que daban forma a este proyecto, no podemos entender el pensamiento pedagógico de Antón Alonso Ríos sin partir de su honda admiración por Francisco Giner de los Ríos, que nace por influencia de Luis López Elizagaray, un ferviente regeneracionista y uno de los destacados institucionistas en el contexto académico gallego. ${ }^{40}$ Antón Alonso admiraba a Giner por haber impulsado una rebelión intelectual contra el gobierno de Narváez y su ministro, el marqués de Orovio; por enfrentarse al arcaico sistema universitario oficial, atenazado

\footnotetext{
${ }^{40}$ La importancia del profesor Luís López Elizagaray fue ya señalada por Antón Costa Rico en Escolas e Mestres. A educación en Galicia: da Restauración á II. ${ }^{a}$ República (Santiago de Compostela: Xunta de Galicia, 1989) y en A Colonia Escolar Compostelana de 1893. Primeiro Centenario. (Santiago de Compostela: Consorcio de Santiago, 1993), de la que López Elizagaray fue promotor.
} 
por el control político reaccionario, y por colocar la primera piedra de un nuevo modelo de sociedad al fundar la Institución Libre de Enseñanza

madre fecunda de toda una legión de hombres cultísimos y dotados de emoción ciudadana, poseídos de un concepto amplio y elevado de la vida social, el cual les llevó a dar a sus enseñanzas, desde la cátedra, desde el libro, desde la prensa, desde la tribuna popular, un contenido vital, un contenido de realidad dinámica generadora de actividad social. ${ }^{41}$

Del mismo modo que Giner había hecho en Madrid a finales del siglo XIX, el líder societario soñaba con levantar en Galicia un proyecto de inspiración institucionista, capaz de transformar la sociedad gallega a partir de la iniciativa de sus hijos en Ultramar. Y así lo manifiesta en Buenos Aires en 1928:

La Federación de Sociedades Gallegas es también un exponente de la iniciativa privada frente a la absorción del Estado; es una manifestación del espíritu que impulsó a Giner de los Ríos a crear la Institución Libre de Enseñanza. Nuestra Federación, creando escuelas y estimulando la vida social en todas sus formas posibles, se esfuerza porque la sociedad se sensibilice y recobre el dominio de sí misma y deje de ser la esclava sumisa del Estado. $^{42}$

Levantar escuelas en Galicia desde la emigración a través de sociedades de instrucción resultó una tarea ejemplar, pero muy heterogénea y descoordinada. Conviene aclarar que en la década de 1920 algunas sociedades fueron construyendo escuelas en sus respectivas parroquias o ayuntamientos, que después entregaban al Estado. Una labor meritoria, cargada de buena intención, pero de escasa conciencia nacional y nulos efectos en el avance político que demandaba la sociedad rural. Esa colaboración con la dictadura de Primo, unida a la «desgalleguización» que aplicaban en su currículum algunas escuelas fundadas por emigrantes

\footnotetext{
41 «Contra la persecución a Jiménez de Asúa realizó un acto de protesta nuestra Federación», El Despertar Gallego 121 (1928): 4.

42 «Contra la persecución a Jiménez de Asúa», 4.
} 
fue severamente criticada en aquel tiempo, además de por la propia Federación, por la Irmandade Nazonalista Galega desde las páginas de su periódico A Fouce: ${ }^{43}$

Mientras allá en la Tierra, se hace poco o nada por la Escuela gallega, los emigrados, con un criterio equivocado, aunque con buena intención, malgastamos esfuerzos y dinero sosteniendo escuelas regidas y orientadas en un sentido ruinoso para Galicia. Nuestras escuelas, las que se sostienen con dinero de América, no se conforman con una labor desgalleguizante [como hacen] las escuelas españolas, van más lejos: desgalleguizan y orientan a nuestros niños hacia la emigración, y para colmar la medida, llegan a obsecuencia servil con los países en que residen los sostenedores, que no otra cosa es la adopción de los textos oficiales de historia, geografía, etc. de estos países de América [...]. La creación de una Sociedad Protectora de la Escuela gallega, es pues, de urgente necesidad, no sólo por el concurso económico que podamos aportar, y por el indudable efecto estimulante que ejercerá en los galleguistas de la Tierra, para alentarlos en tan importante e impostergable obra, sino, porque haría posible la coordinación de muchas voluntades dispersas, para plantear sistemáticamente en el seno de las sociedades que tienen escuelas en Galicia, la necesidad de que se galleguice la enseñanza. ${ }^{44}$

Consciente de ello, Antón Alonso Ríos intentó reagrupar todo ese inmenso trabajo colectivo en una federación de sociedades, en una red organizada y encaminada a un fin concreto: unificar criterios entre las sociedades de instrucción y coordinar sus actividades, especialmente en lo relativo a la intervención escolar, para incrementar el número de escuelas en las respectivas localidades de origen con un ideario laico y una organización graduada de la enseñanza:

\footnotetext{
${ }^{43}$ A Fouce ( $\mathrm{La} \mathrm{Hoz}$ ) fue una publicación de marcado carácter independentista. Era el órgano de la Irmandade Nazonalista Galega de Buenos Aires, más tarde Sociedade Nazonalista Pondal, una de las primeras asociaciones que defendió la independencia de Galicia, e incluso trató de promover un partido independentista. A Fouce se publicó entre enero de 1926 y julio de 1936.

44 «A creazón da escola galega, como toda laboura galeguizante debe contar con orgaizazóns que cordinen e metodicen a acción de todol-os galeguistas». A Fouce 3 (1931): 1 (la traducción y cursivas son nuestras).
} 
Huyamos de cooperar con el Estado. ¡Presentemos nuestra obra en contraste con la oficial! Nada de hacer edificios para las escuelas del Estado, ni tratar de retocar las fallas de su torpe acción ¡Hagamos centros de cultura privados que respondan eficazmente a nuestros anhelos! Así lograremos tres ventajas: restituir a la sociedad el ejercicio de una función, evitar la entorpecedora intromisión oficial en nuestros centros y confrontar la acción social con la del Estado. ${ }^{45}$

Era necesario formar a las clases populares gallegas, del campo y del mar, para evitar su emigración, reteniendo ese "capital humano», tan necesario para la regeneración social y el desarrollo económico del País. Esa federación sería la encargada de crear una red de centros de enseñanza con el nombre de Escuelas Especiales de Economía Rural. ${ }^{46}$ Porque Antón Alonso Ríos ya había comprobado, por su experiencia argentina, que la escuela era el campo fértil donde podía germinar la semilla de una nueva conciencia:

Multipliquemos nuestros centros de cultura con métodos y espíritus nuevos. Hagamos de nuestras escuelas particulares semilleros de ciudadanos; hagamos que cada escuela sea una fuente de conciencia social y de iniciativa privada. La sociedad, así afectada en su embrión, despertará a la vida. ${ }^{47}$

De este modo, cada maestro en cada escuela debía promover la conciencia ciudadana como herramienta eficaz para defender a los campesinos del poder de los blasones, para proteger a las personas de la influencia de las sotanas y liberar las aldeas del control de los caciques.

\footnotetext{
45 Antón Alonso Ríos, «Intensificación cultural», El Despertar Gallego 20 (1923): 1.

${ }^{46}$ Las Escolas Especiais de Economía Rural formaban parte de un plan sobre la formación agrícola en lengua gallega a partir de la enseñanza primaria, a través de un organismo denominado Padroado da Escola Rural Galega. Sus objetivos: orientación y renovación del trabajo campesino incorporando a la enseñanza los nuevos procedimientos de cultivo, cría y selección de ganados, industrias pecuarias y sus derivadas; fomento del cooperativismo, el amor a la tierra y el espíritu comunal; formación de profesorado y edición de libros en lengua gallega para escolares, entre otros objetivos. (Seminario de Estudos Galegos, Actas, Archivo del Instituto de Estudios Gallegos P. Sarmiento, Santiago de Compostela; tomado de Costa, Escolas e mestres, 332).

47 Alonso Ríos, «Intensificación cultural», 1.
} 
Bajo esta premisa nacía la Federación de Sociedades Gallegas, Agrarias y Culturales (FSGAC) el 24 de septiembre de $1921 .{ }^{48}$ Una organización democrática, republicana y laica con una especial sensibilidad hacia el movimiento agrarista gallego, ${ }^{49}$ pues conviene recordar que una inmensa mayoría de los emigrados provenía del mundo rural y muchos de ellos proyectaban allí su retorno, donde habían dejado intereses materiales y anhelos emocionales. Además, la FSGAC también bebía de las fuentes del socialismo y del sindicalismo argentinos, influencia que provenía del proceso de inmersión experimentado por aquellos campesinos convertidos ahora en proletarios urbanos de la sociedad porteña. La publicación de su propuesta política en septiembre de 1922 mostraba un programa muy amplio que trataba de responder a algunas necesidades urgentes de la sociedad gallega. En el orden económico, ejercicio de honradez administrativa y de transparencia fiscal, así como fomento del cooperativismo aplicado a la industria y al comercio; en el político, promoción de los valores democráticos republicanos; en el educativo, fomento de la edificación escolar, promoción del laicismo e innovación pedagógica, dignificación económica y profesional del personal docente y vertebración de la escuela en el mundo rural como medio de desarrollo agrícola, industrial y comercial; y en el orden religioso, separación entre Iglesia y Estado en todos los aspectos, especialmente el educativo y el económico. ${ }^{50}$ Porque, como explicaba Alonso Ríos en El Despertar Gallego respecto de algunas sociedades,

las que sostenían escuelas, salvo raras excepciones, lo hacían sin control y orientación liberal, suministrando una enseñanza con-

\footnotetext{
${ }^{48}$ Ya existía un precedente federativo entre la colectividad gallega radicada en la República Argentina, hacia 1910, con el nombre de Federación de Sociedades Gallegas. Hernán M. Díaz, Historia de la Federación de Sociedades Gallegas (Buenos Aires: Fundación Sotelo Blanco-Biblos, 2007).

${ }^{49}$ Se conoce como movimiento «agrario» O «agrarista» a la organización de los labradores gallegos en sociedades o en sindicatos de distinto signo para luchar contra el sistema foral y el caciquismo, además de promover la innovación técnica y la modernización productiva del sector agrario gallego. Fue el primer movimiento de masas de la edad contemporánea en Galicia, y tuvo cierta intensidad entre finales del siglo xIx y principios del xx, hasta la Guerra Civil, llegando a contar con más de mil organizaciones locales en toda Galicia. Sobre este tema puede consultarse Lourenzo Fernández Prieto y Miguel Cabo Villaverde, «Agrarismo y regeneracionismo en la Galicia de comienzos del siglo xx: El desarrollo del regionalismo agrícola», Agricultura y sociedad 86 (1998): 133-62.

${ }^{50}$ Xosé Manoel Núñez Seixas, Emigrantes, caciques e indianos: o influxo sociopolítico da emigración transoceánica en Galicia (1900-1930) (Vigo: Edicións Xerais de Galicia, 1998), 289.
} 
fusa y en muchos casos clerical. Por otra parte, víctimas de la prédica y del viejo ambiente, fomentado por el mal periodismo español y alguno del país, se asociaban a cuanto acto patriotero se organizase bajo cualquier pretexto, y rendían culto de fe al rey, considerándolo el ángel salvador de España. ${ }^{51}$

Al contrario, las escuelas federadas debían formar una vigorosa corriente opositora que influyera en la caída de la dictadura de Primo de Rivera y de la monarquía borbónica que la sostenía, «esa España funesta de héroes de cartón pintado, reyes monigotes y aristócratas sodomitas, que aguanta y aplaude la tutela vergonzosa de soldados cobardes y de frailes y curas corrompidos». ${ }^{52}$ Ante este panorama, el modelo de enseñanza de las escuelas federadas ayudaría a regenerar cauces de libertad en el pensamiento y en la acción política, ahogados ahora por el Directorio militar. Le correspondía, por tanto, tomar la voz a la ciudadanía: «es la hora de la acción espontánea y libre de la sociedad en el orden educacional frente al monopolio ejercido por el Estado en forma rutinaria y con resultados negativos para el progreso, tanto espiritual como material». ${ }^{53}$

Y en cada escuela, cada maestro debía realizar, también fuera del aula, una labor de estímulo y animación popular en consonancia con las necesidades locales y los fines de la Federación, «encaminando sus esfuerzos a organizar sociedades parroquiales de fomento, y a implantar los métodos económicos de cooperación». ${ }^{54}$ Así lo expresaba en 1927:

¡Hay que llevar al pueblo gallego un germen de vida ciudadana, que arraigue en la mente y en el corazón de la infancia! ¡Es indispensable orientar a la niñez con métodos prácticos hacia el cultivo científico de la tierra, y encaminarla a una inteligente producción y explotación de la riqueza ganadera! ¡Se impone difundir el cooperativismo como medida de emancipación económica! Y en todo esto, la Escuela Moderna está llamada a desempeñar un papel fundamental al que, hoy por hoy, nuestras

\footnotetext{
51 «Nuestra labor de ocho años», El Despertar Gallego 134 (1928): 3.

52 «Alcance espiritual de la Federación», El Despertar Gallego 82 (1926): 5.

53 «En homenaje a Pablo Iglesias», El Despertar Gallego 75 (1926): 1.

${ }^{54}$ «La voz federal», El Despertar Gallego 117 (1928): 3.
} 
escuelas son ajenas casi en absoluto. Mal podemos, pues, sentir cumplidas nuestras aspiraciones. ${ }^{55}$

En todo caso, siendo la institución escolar un buen instrumento, no era ciertamente el único. Esta tarea debía transcender a las aulas, ya que, en ese esfuerzo germinal de nueva ciudadanía, cada una de las entidades federadas debía ampliar su acción y promocionar el cooperativismo, fundar cajas rurales, apoyar a las asociaciones agrarias y crear lo que hoy llamamos tejido socialmente comprometido:

Sabemos que es menester obrar por medio del ejemplo; que se necesita crear la escuela modelo, la granja modelo, la cooperativa modelo, organizar el municipio modelo. A esto vamos, y ya algo se ha hecho, aunque muy imperfectamente por ahora en lo referente a escuelas. Pero estos ejemplos no bastan por si solos. Se necesita la exposición doctrinaria y la incitación constante, y, sobre todo y más que todo, el apostolado. ${ }^{56}$

Seguramente porque las sociedades integradas en la FSGAC se mostraban extremadamente combativas con la dictadura de Primo de Rivera y el entorno social que la sostenía, llegando a ser un eficaz "germen de vida ciudadana», sufrieron el continuo acoso del régimen, apoyado por párrocos y caciques locales contrarios a la labor escolar de los emigrantes, lo que llevó a la clausura de algunas de sus escuelas en diversas ocasiones. ${ }^{57}$ La propia Federación, en una nota desde Correo de Galicia en 1924, daba a conocer las resoluciones de su III Congreso, donde entre otros asuntos relacionados con la política del Directorio, denunciaba «la intromisión del clero en las escuelas en perjuicio del carácter científico de la enseñanza y de la libertad de cátedra, en la familia con detrimento de la patria potestad y en el Estado con desdoro para el poder civil». ${ }^{58} \mathrm{Y}$ en esa perspectiva de crítica política y compromiso

\footnotetext{
${ }^{55}$ El Despertar Gallego 108 (1927): 6.

56 «Acción constructiva. Necesidad del apostolado», El Despertar Gallego 24 (1923): 1.

57 «En Silleda las autoridades no piensan como las de Cospeito», Galicia 193 (1931): 1. Puede consultarse además: Xosé Manuel Malheiro Gutiérrez, As escolas dos emigrantes e o pensamento pedagóxico: Ignacio Ares de Parga e Antón Alonso Ríos (Sada-A Coruña: Ediciós do Castro).

58 «La Federación de Sociedades Gallegas Agrarias y Culturales en la República Argentina. A los agrarios de Galicia», Correo de Galicia 931 (1924): 3.
} 
social destacan algunas de sus resoluciones, entre ellas la de la lucha de clase en defensa del mundo rural:

Para que la obra a realizarse sea eficaz y dé los resultados deseados, debe ser llevada a cabo por las fuerzas agrarias organizadas de Galicia y las radicadas en América, las que deben identificarse y mancomunar sus esfuerzos para trabajar unidas en pro de un régimen sin privilegios ni fueros de ninguna clase..$^{59}$

Vemos, a través de estas notas, cómo muchos de aquellos campesinos gallegos que en la emigración argentina se habían convertido en ciudadanos urbanos, acaban tomando conciencia cívica y reivindican para Galicia los avances sociales y políticos siempre postergados.

En enero de 1922, la FSGAC inicia la publicación de una revista mensual de cabecera, denominada El Despertar Gallego. Órgano de la $\mathrm{Fe}$ deración de Sociedades Gallegas, Agrarias y Culturales de la República Argentina, con el fin de «defender los más caros ideales: la patria lejana, el amor a nuestros semejantes; el ansia de progreso, de paz, de justicia, de libertad, así como combatir el caciquismo y alentar al pueblo gallego para su emancipación» ${ }^{60}$ El Despertar Gallego, posteriormente Galicia, bajo la dirección de Alonso Ríos la mayor parte del tiempo, gozaba de una tirada media de quince mil ejemplares, de los que una parte se distribuía en Galicia, si bien las autoridades municipales en algunos ayuntamientos trataron de impedir su difusión por los motivos antes señalados. ${ }^{61}$ Serán también El Despertar Gallego y Galicia, entre otras publicaciones, las tribunas donde el líder societario plasme las líneas de su pensamiento político y pedagógico, como veremos, para apoyar, organizar y dirigir el rumbo del movimiento agrarista: «Caciquismo

\footnotetext{
59 «Declaración de principios y programa de acción de nuestra Federación», El Despertar Gallego 124 (1928): 1.

${ }^{60}$ En 1930 cambia su cabecera por Galicia. Publicación semanal editada por la Federación de Sociedades Gallegas. Portavoz de la Federación de Sociedades Gallegas.

${ }^{61}$ Núñez, Emigrantes, caciques e indianos, 293. El propio semanario denunciaba en julio de 1924: «El Directorio Militar ha prohibido la entrada de nuestro órgano oficial en la nación; los curas desde sus púlpitos señalan a El Despertar Gallego como una hoja endemoniada de la que debe huir todo aquel que no quiera exponerse a la condenación eterna, mientras los paisanos hacen circular de mano en mano los escasos ejemplares que logran burlar la censura, bebiendo en ellos la doctrina democrática que conforta sus espíritus abatidos por la más odiosa tiranía», El Despertar Gallego 31 (1924): 1.
} 
y clericalismo — ¡Nunca me cansaré de repetirlo! — son las dos grandes plagas, los dos eternos azotes que hay que combatir. Representan el privilegio y la arbitrariedad; y por principio, hemos de mantenernos siempre frente a ellos. Si no lo hacemos así, habremos sido inconsecuentes, habremos claudicado».62

En 1926, la FSGAC incorporaba a su ideario los valores del movimiento nacionalista gallego, "que al son triunfal de himnos de libertad, irrumpe en el escenario de la historia del brazo del movimiento proletario y guiado por los más caros principios de la democracia y los luminosos postulados de la ciencia político-social contemporánea». ${ }^{63} \mathrm{De}$ este modo crecía la ilusión entre un grupo de entusiastas desde América para implantar un régimen democrático en Galicia de sólida base republicana, amplia representatividad social y nítida identidad cultural, en el que la educación de las clases populares, del campo y del mar, sería el principal objetivo. También, de este modo, se marcaba el camino a los más de 3.500 asociados y la FSGAC va a convertirse en un elemento muy importante en la política y en general en el panorama ideológico de Galicia, desde su fundación hasta la Guerra Civil. ${ }^{64}$

\section{REPÚBLICA, GALLEGUISMO Y PREOCUPACIÓN POR LA ESCUELA RURAL}

Iniciada esta etapa — «Gracias a la proclamación de la República, los gallegos emigrados tenemos ahora una patria, una bandera y dejamos de ser los eternos proscritos»-, ${ }^{65}$ empiezan los primeros movimientos políticos encaminados a promover y aprobar un Estatuto de autonomía en el marco de un estado federal:

He ahí el problema general planteado en términos que no admiten dos soluciones: o los pueblos de Iberia todos a la vez

\footnotetext{
62 Antón Alonso Ríos, «Carta abierta», El Despertar Gallego 14 (1923): 3.

63 «Una declaración ampliamente documentada», El Despertar Gallego 151 (1929): 3.

${ }^{64}$ En 1930, por problemas relacionados con algunas luchas internas entre socialistas y republicanos federalistas, la FSGAC se divide en dos entidades: la Federación de Sociedades Agrarias y Culturales de tendencia republicana y nacionalista, donde permanece Alonso Ríos con su nuevo órgano, Galicia, y la Federación de Sociedades Gallegas, de orientación socialista, que acabó editando su propio órgano Acción Gallega.

65 «En celebración de la República española», Galicia 204 (1931): 1.
} 
arriman el hombro para arrojar la monarquía y con ella el centralismo, el militarismo, el clericalismo y los caciques, o se resigna a ver que por incomprensión y cobardes, la presente hora quede grabada en la historia nacional y regional como una nueva frustración de nuestros designios. ${ }^{66}$

Alonso Ríos acepta viajar a Galicia junto con otros compañeros, comisionados por la FSGAC «para luchar, en el corazón mismo de la tierra, por los ideales de redención y democracia sostenidos durante tantos años en la inmigración, e inculcados a tantos de nosotros», ${ }^{67} \mathrm{y}$ defender "con énfasis y ardor el control exclusivo de todos los niveles do enseñanza por parte del poder gallego, así como la plena identificación de los contenidos con la realidad nacional: "Queremos que el maestro gallego haga ciudadanos gallegos" $\gg .68$

Por su independencia y su prestigio, el maestro y líder societario, y ahora incipiente político, cuenta con la aprobación mayoritaria de la colectividad para desempeñar un papel integrador entre las diferentes sensibilidades, y sobre todo para recabar el apoyo popular necesario al proyecto del futuro Estatuto de Autonomía ${ }^{69}$ elaborado por el Seminario de Estudos Galegos. ${ }^{70}$ Durante este periodo de su vida y hasta el golpe de Estado del 36, desarrolla una intensa actividad política mi-

\footnotetext{
${ }^{66}$ Antón Alonso Ríos, «Orientación», Galicia 196 (1931): 4.

67 «Antonio Alonso Ríos sale para España el martes», Galicia 205 (1931): 1.

68 «De la histórica Asamblea de La Coruña», Galicia 211 (1931): 1.

${ }^{69}$ En mayo de 1931, el Seminario de Estudos Galegos emprendió la tarea de elaborar un proyecto de Estatuto que, junto a otros documentos presentados, no fueron aceptados por las fuerzas gallegas mayoritarias. Un nuevo intento con una implicación muy intensa del Partido Galeguista (PG) pudo ser aprobado en 1932. Pero el veto impuesto a toda iniciativa autonomista por la coalición radical-cedista frenaron toda posibilidad de plasmación política hasta junio de 1936, que con el Frente Popular en el poder, y tras una intensa campaña, permitió su aprobación popular mayoritaria. Aun así, Galicia no pudo aplicar el Estatuto aprobado a causa del golpe militar y la guerra civil. A partir de 1944, Antón Alonso Ríos formaría parte, junto a Castelao, del Consello de Galicia, una especie de gobierno gallego, pero ya desde el exilio.

${ }^{70}$ El SEG nacía en 1923 siguiendo el espíritu de la JAE y teniendo en consideración la experiencia del Seminari d'Estudis Cataláns, por iniciativa de un reducido grupo de profesores y alumnos de la Universidad de Santiago de Compostela con el objetivo de promover las diferentes manifestaciones de la cultura gallega mediante la realización de estudios e investigaciones históricas y arqueológicas con carácter científico e interdisciplinar y la difusión de sus resultados, fundamentalmente en lengua gallega. Fue desmantelado después del golpe de estado, y reconvertido en el Instituto de Estudios Gallegos Padre Sarmiento pasando a depender del CSIC en 1944. Puede consultarse: Alfonso Mato, O Seminario de Estudos Galegos (Sada-A Coruña: Ediciós do Castro, 2001).
} 


\section{litando en el Partido Galeguista (PG) ${ }^{71}$ y luchando al lado del movi- miento agrario:}

El labriego emigrará de Galicia mientras la campiña gallega no sea objeto de mayor atención por parte de quien sea capaz de resolver el problema. A tal extremo ha llegado la división de la propiedad y tales los impuestos que pagan, que cada parcela de tierra que el labriego adquiere no es más que un eslabón que agrega a su cadena de esclavo. ${ }^{72}$

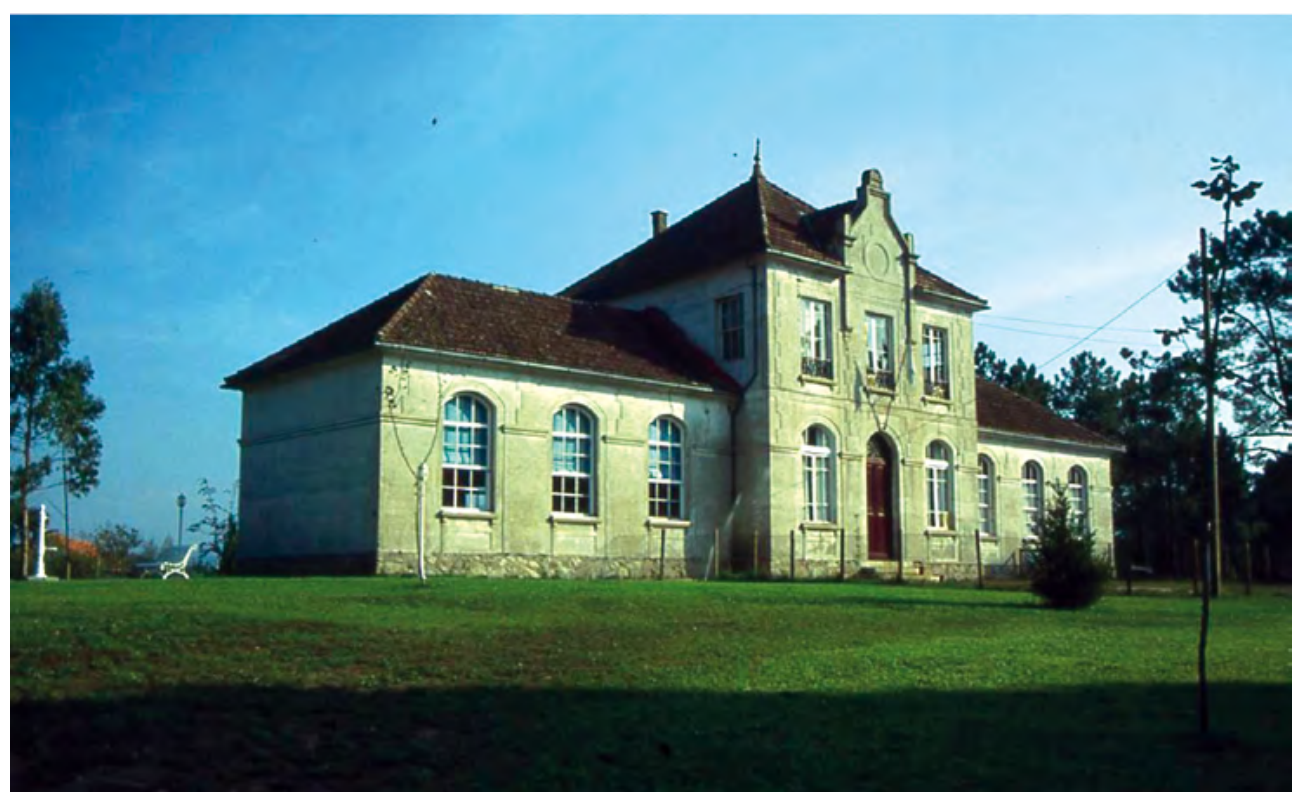

Imagen 4. Escuela «Aurora del Porvenir» en Tomiño (Pontevedra), sostenida por emigrantes gallegos residentes en el Brasil y la Argentina, donde el maestro ejerció entre 1931 y 1936

${ }^{71}$ El PG se fundó en diciembre de 1931, como resultado de la fusión de diferentes grupos nacionalistas locales, para reivindicar la autodeterminación política de Galicia en el marco de una perspectiva federalista con una orientación reformista y moderadamente progresista. Tenía un carácter integrador e interclasista, prestando especial atención a los problemas del mundo rural como depositario de los rasgos identitarios de la nacionalidad gallega, tratando de captar en ese ámbito una parte importante de su capital. El PG fue un proyecto donde confluyeron posiciones conservadoras como las que defendían Vicente Risco, Otero Pedrayo o López Cuevillas, y otras progresistas como la que representaban Castelao, Alexandre Bóveda o Ánxel Casal, pasando por grupos de izquierda más radical, con los que se identificaban Suárez Picallo, Villar Ponte o el propio Alonso Ríos. Xosé Manoel Núñez Seixas, O galeguismo en América, 1879-1936 (Sada-A Coruña: Ediciós do Castro, 1992), 212.

72 «La costumbre gallega de emigrar», El Despertar Gallego 120 (1928): 1. 
Su primera visita oficial en suelo gallego es a las escuelas de la Sociedad de Silleda, en su tierra, «siendo recibido con grandes muestras de consideración por los maestros y alumnos de las mismas, y despedido con vivas y aplausos cariñosos ${ }^{73}$ antes de viajar a Coruña para presidir la Asamblea para el estudio del Anteproyecto de Estatuto de Autonomía. En esta Asamblea sale elegido candidato de la Federación Republicana Gallega a las elecciones del 28 de junio de $1931 .{ }^{74}$

Las ventajas del régimen autonómico no estriban en la eliminación del parasitismo burocrático, con ser ello de la más alta importancia; su más halagadora promesa radica precisamente en el nuevo concepto que en oposición al mantenido por el régimen centralista, él trae de la administración local el fijar como finalidad medular de la misma los intereses locales, y darle categoría de fuerza social creadora, en lugar de dejarla reducida al papel subalterno y pasivo de simple instrumento del poder central. $^{75}$

En el mes de septiembre, al no ser elegido parlamentario, se instala con su familia en el ayuntamiento de Tomiño (Pontevedra) aceptando el puesto de director de la escuela «Aurora del Porvenir» ${ }^{76}$ y de Inspector técnico de las escuelas que sostenían las sociedades federadas — «Conocido es el intenso amor que Alonso Ríos siente por las cuestiones educacionales, y no es de dudar que al frente de la institución que ahora le nombró director ha de desarrollar una labor eficaz y digna de

\footnotetext{
73 «Alonso Ríos en Galicia», Galicia 211 (1931): 2.

${ }^{74}$ Junto al resto de representantes de los emigrados, aunque posteriormente se cae de la lista sin ninguna explicación pública, debido con toda probabilidad al veto de Casares Quiroga por las dinámicas internas de las formaciones políticas y sus distintas formas de entender la causa autonomista. «En Lugo, Ribadeo, Meira y Fonsagrada son recibidos con gran entusiasmo los representantes de los emigrados», Galicia 215 (1931): 5.

75 «Sobre autonomía regional. El pretendido crecimiento burocrático», Galicia 238 (1931): 1.

76 «Aurora del Porvenir» había sido creada por la sociedad Aurora del Porvenir pro Instrucción, integrada por emigrantes residentes en Río de Janeiro con delegaciones en Buenos Aires y Lisboa para «costear una Escuela práctica de acuerdo con los planteamientos modernos en la que puedan [los alumnos] gratuitamente recibir la instrucción moral e intelectual», que gozaron de instalaciones modernas, con espacios para el estudio, la práctica de deportes y un campo de experimentación agrícola, siguiendo criterios pedagógicos inspirados en el modelo argentino. Xosé Manuel Malheiro Gutiérrez, Herdanza da emigración ultramarina (Pontevedra: Deputación de Pontevedra, 2005), 97-98.
} 
su prestigio»-.${ }^{77}$ Este puesto le permite vivir y poder dedicarse a la misión política encomendada por la FSGAC. En este tiempo participa en la Federación Agraria del Partido Judicial de Tui e interviene muy activamente en la constitución del PG, significando una pieza clave en su vinculación con el movimiento agrarista, ${ }^{78}$ tanto para "galleguizar» este enorme potencial que representaban las sociedades agrarias - muy vinculadas al contexto migratorio, de donde recibían importantes recursos-, como para influir en las resoluciones del PG respecto de los problemas del mundo rural. ${ }^{79} \mathrm{Su}$ perfil integrador posibilitó la convivencia de corrientes políticas muy diferentes dentro de esta organización. ${ }^{80}$

Después de haber trabajado más de una década en el sistema educativo argentino, su nueva experiencia como maestro en la escuela «Aurora del Porvenir» le confirma lo que ya había expresado en la revista Céltiga en 1926, que en Galicia, en materia educativa, todavía estaba todo por hacer:

Nuestras escuelas están mal organizadas y peor atendidas, en lo que se refiere a locales, material de enseñanza y maestros. Los niños de las aldeas no adquieren en esos centros de enseñanza ni amor al trabajo y al estudio, ni ese santo cariño a la generosidad de la tierra, y a la sagrada vida del hogar, que recién aprecian después, cuando la realidad de la emigración les hace distinguir entre el valor de los que dejaron allá y lo que encuentran en estos países, donde las aptitudes se someten a dura prueba. ${ }^{81}$

\footnotetext{
77 «Antonio Alonso Ríos», Galicia 230 (1931): 3. Su familia ya había sido reclamada por él y embarcaba a finales de agosto. Ver Galicia 221 (1931): 2.

${ }^{78}$ Núñez, O galeguismo en América, 238.

${ }^{79}$ Antón Garazo, «Silleda e a comarca de Deza: políticos de onte e políticos de hoxe», A Trabe de ouro. Publicación galega de pensamento crítico 9 (1992): 41.

${ }^{80}$ Marcos Valcárcel, «La segunda república», en Historia de Galicia. Tomo IV. La época contemporánea (Vigo: Faro de Vigo/Caixavigo, 1991), 933. El propio Alonso Ríos, dos días antes de las elecciones de junio de 1931, llegó a reivindicar un Estado gallego, y hablaba de hacer la revolución en la calle: «Yo os conjuro, ciudadanos, a que de una vez hagamos nuestra revolución por encima de todos los poderes centrales habidos y por haber, proclamando nuestra independencia y abrazándose, si hace falta, cariñosamente a Portugal nuestra hermana». Incluso fue nombrado presidente de la «Junta Revolucionaria de Santiago» a la espera de adhesiones de otras ciudades gallegas, que no llegaron. Ver El Pueblo Gallego 2255 (1931): 4. También Núñez, O galeguismo en América, 210.

81 «Temas del agro gallego. Las ideas nacionalistas en la vida del labrador», Céltiga 31 (1926): s.p.
} 
Antón Alonso Ríos nos dejó un legado teórico, relacionado con el mundo de la educación formado por ideas y reflexiones de carácter general, basadas en la praxis, que son el núcleo de su particular visión del modelo de enseñanza que quería para Galicia. Fragmentos que difundió, fundamentalmente, a través de la prensa periódica argentina y gallega. Porque nuestro personaje fue, sobre todo, un hombre de acción, tanto en el campo político como en el pedagógico.

Como fruto de sus experiencias en la Argentina y en Galicia, en el año 1935 publica en El Pueblo Gallego ${ }^{82}$ una serie de trabajos -cuatro de ellos bajo el epígrafe "Defectos de nuestra escuela rural»— ${ }^{83}$ en los que, desde una óptica nacionalista, elabora un diagnóstico de la realidad educativa y denuncia algunos problemas que, como la graduación de la enseñanza, la adaptación del calendario escolar a las peculiaridades del entorno agrario, la reforma del modelo de inspección o la necesidad de un currículum propio en lengua gallega, requerían, a su juicio, una atención inmediata.

En «Defectos de nuestra escuela rural. Su carácter unitario», sobre la escuela unitaria o graduada pregunta: «¿Qué otra clase de enseñanza, ni moderna ni antigua, ni propia ni impropia, que no sea el simple leer, escribir y contar, y las cuatro nociones rudimentarísimas de un conocimiento general, puede suministrarse a un conjunto dispar de alumnos de 6 a 14 años, que concurren a las clases con intervalos de semanas y aún de meses?». Su propuesta es la graduación de la enseñanza:

En nuestras aldeas es facilísimo establecer la escuela graduada. Fácil y además económico. Sus bases son la coeducación y el turno único para el alumno y doble para el maestro. La graduación puede ser inmediata. Cada escuela actual podría tener una escuela infantil por la tarde y por la mañana el que le correspondiera dentro del ciclo de la graduada. Un local central

\footnotetext{
${ }^{82}$ Periódico vigués de difusión regional y orientación liberal, que prestó una atención especial a los problemas del magisterio a través da su sección «La enseñanza y los maestros». Su propietario, a partir de 1927 fue Manuel Portela Valladares, presidente del gobierno de la República con Alcalá Zamora, habiendo sido ya ministro en ocasiones anteriores.

${ }_{83}$ Artículos que, junto a algunos otros de El Despertar Gallego, ya tomó en consideración Costa Rico en su trabajo Escolas e mestres, y que ahora retomamos en el empeño de componer el perfil de Alonso Ríos.
} 
para los grados de especialización en cada término municipal. En él, la dirección, los archivos, servicio médico, etc. ${ }^{84}$

Otra de sus preocupaciones era el absentismo escolar, uno de los grandes problemas de la escuela gallega en ese momento. Como es sabido, en Galicia en ese tiempo, con excesiva frecuencia en las familias, el trabajo del campo quedaba a cargo de la mujer y de los hijos menores, "pues el esposo y los hijos mayores huyen por necesidad y por rutina del improductivo trabajo de la tierra hacia la emigración, el mar, los oficios o los trabajos públicos». En «Defectos de nuestra escuela rural. Régimen de vacaciones inadaptable», exige un calendario lectivo adaptado a las condiciones de la producción agropecuaria con un régimen de vacaciones acorde al ritmo de los cultivos. Un turno único, de mañana o de tarde, "vendría a hacer compatible la asistencia escolar con la imprescindible necesidad que tienen nuestros labradores de los servicios de sus hijos desde temprana edad». Sobre esto afirma que

de nada sirve mantener la escuela abierta cuando los niños no concurren a ella. Hay que aprovechar aquellas épocas del año que dejan libres los trabajos más intensos de la labranza y de la recolección, durante los cuales el labrador puede prescindir de la cooperación de los menores. [...] Las vacaciones, en un país sometido a condiciones económicas tan duras que se hace imprescindible el trabajo del niño durante la edad escolar, necesariamente han de estar supeditadas, antes que a otra razón alguna, a las posibilidades de una mayor asistencia a la escuela. ${ }^{85}$

Califica de «verdadero despropósito» celebrar vacaciones en el mes de abril, y propone que las de verano sean durante los meses de mayo y junio, los meses de mayor intensidad en las faenas del campo, ya que julio, agosto y septiembre son más indicados para las clases:

Hay que adaptar las vacaciones al medio aunque se resientan los principios de la Pedagogía normal. Hace falta una Pe-

\footnotetext{
${ }^{84}$ Antón Alonso Ríos, «Defectos de nuestra escuela rural. Su carácter unitario», El Pueblo Gallego 3507 (1935): 1.

${ }^{85}$ Antón Alonso Ríos, «Defectos de nuestra escuela rural. Régimen de vacaciones adaptable», El Pueblo Gallego 3509 (1935): 1.
} 
dagogía anormal para esta tierra. Una pedagogía que estudie y prefiera las reglas necesarias para la mejor educación posible de los niños normales en un medio anormal. Y esta Pedagogía es la que necesita Galicia, mientras dure la esclavitud económica. ${ }^{86}$

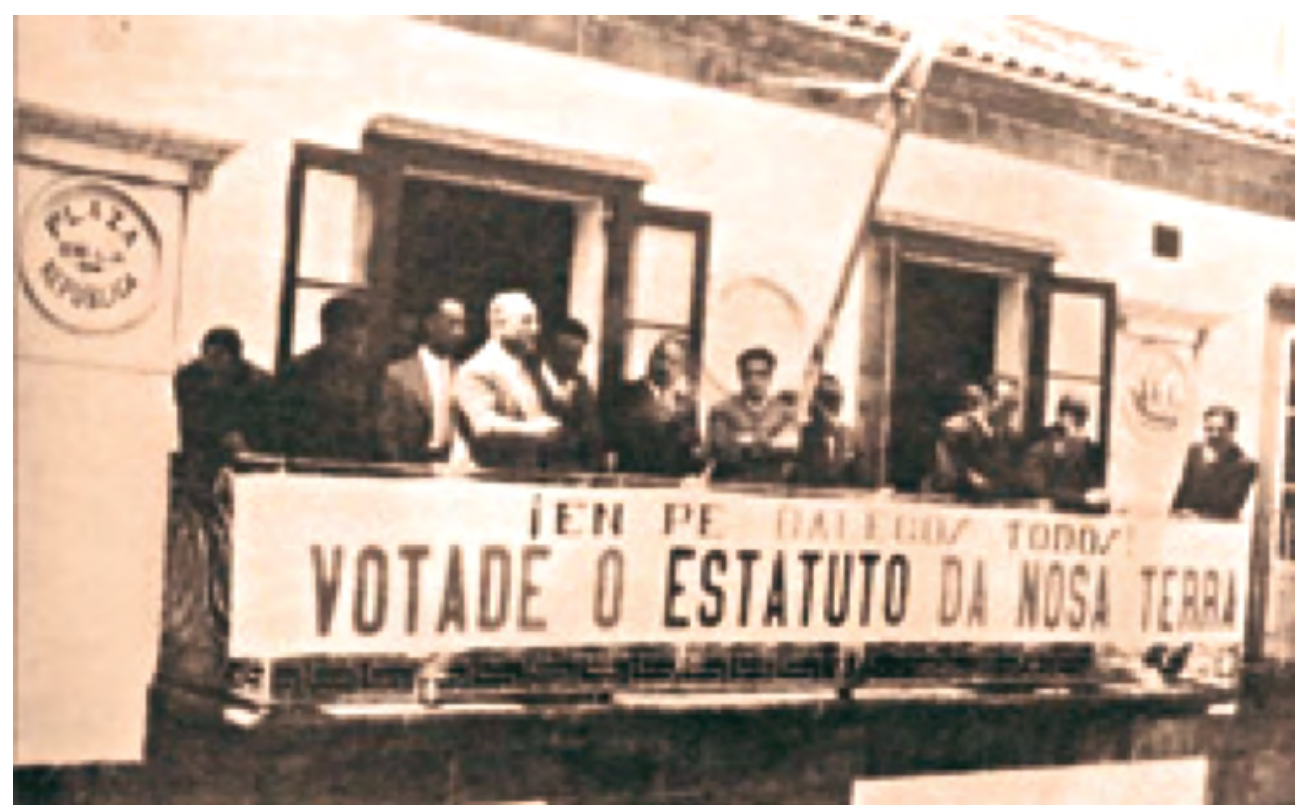

Imagen 5. Antón Alonso Ríos político. Mitin a favor del Estatuto de Autonomía en A Guarda (Pontevedra) en 1936, con Víctor Fráiz, maestro asesinado en Castrelos (Vigo) en septiembre 1937

En «Defectos de nuestra escuela rural. Inspección burocrática», 87 sostiene con ironía que los servicios de inspección se encuentran muy atareados en labores burocráticas «para poder ocuparse de innovaciones». La «llamada inspección técnica parece que aspirase a llenar un triple cometido: iniciativa, administración y control. Solo llena cumplidamente el segundo y eso a fuerza de desatender los otros dos, que son los esenciales de la función inspectora, convirtiéndolo en un eslabón más de la cadena burocrática». Define al inspector escolar como

\footnotetext{
${ }^{86}$ Alonso Ríos, «Régimen de vacaciones adaptable», 1.

${ }^{87}$ Antón Alonso Ríos, «Defectos de nuestra escuela rural. Inspección burocrática», El Pueblo Gallego 3512 (1935): 1.
} 
«ave de paso, sin tiempo para desarrollar una fecunda iniciativa: nada de clases modelo, ni un ensayo, ni una tentativa siquiera que pretenda la cooperación social a la función docente, la vinculación de la escuela con el hogar o el quebrantamiento de la rutina casi secular». Esta figura administrativa sería, por tanto, el primer elemento a transformar dentro de un engranaje que afectaría al conjunto de los recursos humanos, materiales y organizativos, pasando de un modelo de inspección burocrática hacia otro modelo emprendedor, independiente y próximo al medio. Con respecto al personal docente, la nueva inspección escolar tendría como uno de sus trabajos «transformar un profesorado amorfo sin el adiestramiento necesario para las nuevas modalidades del actuar docente y social. Sin el aprendizaje requerido para la investigación y aun para la docencia de nuevas disciplinas. Entumecido por la rutina, influido por la quietud aldeana». ${ }^{88}$

En «Defectos de nuestra escuela rural. Exotismo», sostiene que la escuela rural moderna exige coordinación entre la función inspectora y la función docente, que deben caminar unidas y beneficiarse de recíprocas influencias: la escuela reclama apoyo y control por parte de la inspección, y ésta demanda una forma propia de hacer escuela, para evitar lo que denomina exotismo, es decir, la implantación de métodos, recursos y normas ajenos a las necesidades de la realidad gallega:

Este maestro que habla castellano, que debe pensar en castellano, que debe tener una sensibilidad esteparia es el encargado de dirigir la educación de nuestros niños, es el encargado de hacer «insensible» la transición entre el hogar y la escuela. ¡Y para esto se tiene escuelas Normales y se estudia Pedagogía! Y hay maestros gallegos que ven como la cosa más lógica ese salto mortal del hogar gallego a la escuela castellana! ¡Infelices, si saben hacer honor a la más noble de las profesiones que tiene la vergüenza de contarlos entre sus filas! ${ }^{89}$

Exige un modelo escolar propio para Galicia, y critica planes de estudios implantados con criterios foráneos, así como la presencia de

\footnotetext{
88 Antón Alonso Ríos, «El inspector en su medio», El Pueblo Gallego 3529 (1935): 16.

${ }^{89}$ Antón Alonso Ríos, «Defectos de nuestra escuela rural. Exotismo», El Pueblo Gallego 3513 (1935): 16.
} 
maestros que hablaban un idioma extraño: «Tenemos maestros exóticos, idioma exótico, material exótico. En nuestras escuelas rurales todo está dispuesto para la incomprensión». ${ }^{90}$ Este conjunto de factores venía a explicar el abandono, el consiguiente atraso social y las remotas posibilidades de cambio en un futuro inmediato.

A la visión crítica y pesimista de estos artículos, en los que analiza cuatro de los «pecados capitales» del modelo educativo gallego, se añade otra serie en los que aborda diversos aspectos centrados en la inspección:

Los maestros están en lo cierto. La presencia del inspector es absolutamente necesaria en todo tiempo, pero de modo especial en los momentos actuales, en que se impone un cambio fundamental, de forma y de fondo, que tenemos que dar un salto de más de un siglo para poner nuestra escuela rural a tono con las exigencias de la cultura y de la economía, que no se concibe una escuela fuera de estos imperativos categóricos: el niño y su medio. El niño, en sus diversas etapas de formación, concebidas cada una como una necesidad, como un mundo. El medio, no sólo en relación con nuestros sentimientos y sensaciones, por lo que toca a los supremos valores morales y estéticos, sino por su aspecto utilitario. ${ }^{91}$

Sostiene Alonso Ríos que, gracias a la nueva coyuntura republicana, el inspector de escuelas tenía en sus manos la posibilidad de adaptar la escuela a la ciencia y al medio, pero «¿Se siente capaz de acometer esta obra? ¿Prefiere la vida cómoda del burócrata provinciano al papel de creador de la nueva escuela rural gallega y de la vida aldeana que la suerte le depara? Él y el tiempo nos darán la respuesta». ${ }^{92}$

Y como docente, como inspector técnico y también como líder político, visita con cierta frecuencia las escuelas de la Federación. Queremos señalar una de esas ocasiones en Silleda, con motivo de la fiesta escolar del $1 .^{\circ}$ de mayo de 1932, en la que se congregaban alumnos, padres

\footnotetext{
${ }^{90}$ Alonso Ríos, «Exotismo», 16.

${ }^{91}$ Antón Alonso Ríos, «Síntoma halagador. El Magisterio oficial enfoca el problema de la enseñanza rural», El Pueblo Gallego 3526 (1935): 1.

92 Alonso Ríos: «El inspector en su medio», 16.
} 
y profesores de las escuelas promovidas por la sociedad. Había llegado desde Tomiño, y participaba acompañado de varios compañeros políticos dirigiéndose a «un inmenso gentío congregado en el campo de la escuela donada por los hijos de Silleda en América». En su intervención advertía que no sólo el Estado era culpable del atraso que padecía Galicia, sino también los vecinos por su pasividad y colaboración con gobiernos ajenos: «La República tiene resueltos ya el problema de la libertad individual y de la presión clerical, pero en cambio no ha resuelto el de la libertad de las regiones sino que, por el contrario, en este aspecto, alienta las mismas miras imperialistas de la monarquía». ${ }^{93}$ Vemos, cómo, influido por el regeneracionismo de finales del XIX y como militante del movimiento galleguista de principios del xx, demostraba una honda preocupación por el modelo de Estado y su confianza en los cambios sociales. Era preciso elevar el nivel cultural de la ciudadanía para avanzar en el desarrollo de lo que el denominaba «una solidaridad consciente», y la escuela era uno de los instrumentos más indicados para presentar alternativas vitales y abrir nuevos cauces de regeneración social.

En las elecciones de febrero de 1936 es elegido diputado en las listas del Frente Popular, representando a la Federación Provincial Agraria de Pontevedra. A pesar de las dificultades estructurales de la propia política y del entorno centralista madrileño, interviene en sucesivas ocasiones entre marzo y julio de 1936, con preguntas e interpelaciones sobre cuestiones relativas a la modificación de la Ley de Reforma Agraria, la abolición de los foros, la necesidad de llevar a cabo una concentración parcelaria, la crisis del sector maderero, la necesidad de frenar el desempleo, la solución de la crisis pesquera o la derogación de la ley sobre el voluntariado en el ejército: «Nuestras fábricas de conservas, nuestros aserraderos no pueden traducir su contribución industrial en aumento de precio de la lata de sardinas o del metro de madera, tal como lo hace el fabricante vasco, asturiano, catalán, levantino o andaluz por tener que venderlos en competencia con los productos extranjeros». ${ }^{94}$

En este mismo 1936 participa activamente en la Campaña pro-Estatuto visitando los sindicatos agrarios de la provincia e interviniendo

\footnotetext{
93 «Se intensifica en toda Galicia la campaña galleguista. Grandiosos mítines en Escuadro y Laro (Silleda)», Galicia 262 (1932): 2.

94 Antón Alonso Ríos, «Carácter de nuestra contribución industrial», Galicia 413 (1935): 3.
} 
en decenas de mítines con la esperanza de que Galicia inaugurase una etapa democrática y de desarrollo económico, porque el Estatuto de Autonomía era fundamental para poder corregir el atraso que padecía el país. La campaña remató el domingo 28 de junio y la ciudadanía gallega salió a votar. El resultado fue altamente favorable al «SI». El día 16 de julio, después del acto de entrega oficial del Proyecto al presidente Azaña en la capital del Estado, Alonso Ríos regresa a Tomiño para descansar y ocuparse de la «Aurora del Porvenir». Dos días después se produce el golpe de Estado que desemboca en la guerra civil, y con él empieza una persecución implacable por parte de los falangistas, que ya habían puesto precio a su cabeza. Como explica Álvarez Blázquez, en un intento desesperado por contribuir a salvar la democracia y la libertad, se puso al frente de un pequeño grupo de carabineros, soldados de la marina y paisanos armados con escopetas de caza en los primeros momentos de la rebelión militar. ${ }^{95}$

\section{LA REPRESIÓN FASCISTA: CON AFRANIO DE AMARAL Y SUS EXILIOS}

El golpe de Estado comandado por el general Franco significó, sin duda alguna, la ruptura violenta del régimen político constitucional republicano y abrió, a partir de ese momento, durante toda la guerra civil y en el primer franquismo, un período de muertes, encarcelamientos, castigos administrativos y exilios que, pese a abarcar a toda la sociedad gallega, se cebó significativamente en los diferentes cuerpos docentes. Afirma Federico Cocho que los sublevados reservaron para el magisterio «una tenaz criba que tenía como objetivo barrer de las aulas aquella generación de maestros y maestras, implicada en la aplicación en la escuela, de las ideas modernizadoras de la República». ${ }^{96}$

\footnotetext{
95 Álvarez, «Prólogo», 20.

${ }^{96}$ Federico Cocho de Juan, Guerra Civil. Que pasou en Galicia e en España (Vigo: Edicións Xerais de Galicia, 2011), 308. La represión franquista en Galicia viene siendo objeto de atención desde hace algunos años. Entre los diferentes autores y sus trabajos, nos interesa destacar, además de a Federico Cocho, para el Estado, a Francisco Morente Valero, La escuela y el Estado Nuevo. La depuración del Magisterio Nacional (1936-1943) (Valladolid: Ámbito Ediciones, 1997); (2001), y «La muerte de una ilusión: el Magisterio español en la Guerra Civil y el primer franquismo», Historia y Comunicación social 6 (2001): 187-201; Antonio Viñao Frago, "Memoria escolar y guerra civil. Autobiografías, memorias y diarios de maestros y maestras», Cultura Escrita \& Sociedad 4 (2007): 171-202. Para el ámbito de Galicia deben consultarse: Xosé Manuel Cid Fernández, Educación e
} 


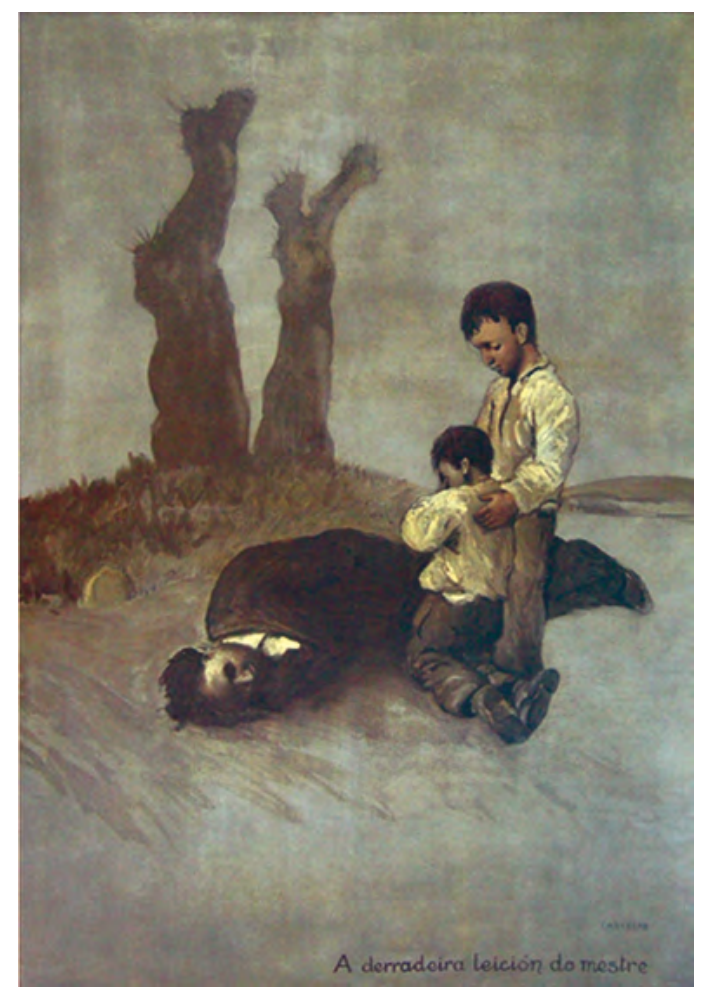

Imagen 6. «A derradeira lección do mestre». 1937. (C) Editorial Galaxia y herederos de Castelao.

Óleo sobre tela pintado en 1945, ya en el exilio, expuesto en el Centro Galicia (Buenos Aires), en el que Castelao retrata la salvaje represión fascista contra el magisterio republicano. La víctima representa a Alexandre Bóveda, maestro y compañero político de Alonso Ríos en el Partido Galeguista, asesinado en Poio (Pontevedra), en agosto de 1936

ideoloxía en Ourense na II República. Organización e acción socioeducativa do maxisterio primario (Santiago: Andavira, 2010); Antón Costa Rico, «Os ensinantes galegos e o 36. Os mortos e os exiliados», en A II. ${ }^{a}$ República e a Guerra Civil, ed. VV. AA. (A Coruña: Deputación de A Coruña, 2006), 487-521; Narciso de Gabriel, "Arximiro Rico: vida e morte dun mestre republicano», Sarmiento. Anuario Galego de Historia da Educación 4 (2000): 9-38, y «Republicanismo e educación», en El republicanismo coruñés en la historia, (A Coruña: Concello da Coruña, 2001), 257-266. Ricardo Gurriarán, Ciencia e conciencia na Universidade de Santiago (1900-1940) (Santiago de Compostela: Servizo de Publicacións da Universidade, 2006); Ánxo Porto Ucha, Mestras e mestres pontevedreses depurados polo franquismo. Primeiras accións represivas e estudo por concellos no sur da provincia (1936-1942) (Ponteareas: Alén Miño, 2008); Sabela Rivas Barrós, A derradeira lección dos mestres. Galeguismo e pensamento pedagóxico (1900-1.936) (Vigo: Edicións Xerais de Galicia, 2001); María José Souto Blanco, La represión franquista en la provincia de Lugo (1936-1940) (Sada-A Coruña: Ediciós do Castro, 1998); Anos de odio. Golpe, represión e Guerra Civil na provincia da Coruña (1936-1939) (A Coruña: Deputación da Coruña, 2007); Alberto Valín Fernández, Laicismo, educación y represión en la España del siglo XX. Orense, 1909-1936/39 (Sada-A Coruña: Ediciós do Castro, 1993). Cfr. Antón Costa Rico y Xosé Manuel Malheiro Gutiérrez, «La investigación histórico-educativa en Galicia, 2002-2014», Historia y Memoria de la educación 4 (2016): 307-335. 
Pese a esquivar una muerte casi segura en el momento posterior al golpe de estado, «el indeseable Alonso Ríos, Diputado marxista de lo más acentuado ${ }^{97}$ se vio forzado a desaparecer de la escena pública para no caer, usando sus propias palabras, en las "garras de la muerte». ${ }^{98} \mathrm{Y}$ aquí dan comienzo sus dos exilios. El primero se inicia el día 26 de julio de 1936 desde su vivienda en la casa-escuela "Aurora del Porvenir» en Tomiño, y le obliga a recorrer caminos, a cruzar montes, a ocultarse en la fronda boscosa como un vulgar salteador perseguido por la «ley», hasta el norte fronterizo portugués, oculto bajo la falsa identidad de Afranio do Amaral. Como explica Álvarez Blázquez en el prólogo del libro, durante tres largos años anduvo por carreteras y caminos; paró en las posadas, durmió al raso o en los graneros, pidió limosna en las ferias, trabajó de criado al jornal: «aprendí trabajos que nunca había hecho: podar, atar, injertar y cavar las viñas; catar las colmenas, segar la hierba con la guadaña. Y me puse bien práctico en arar». ${ }^{99} \mathrm{El}$ destierro le obligó a bordear la vivienda de algún amigo y continuar de largo, para no complicarles su situación:

llegué delante de la escuela donde mi amigo, maestro y poeta Victoriano Taibo, con un puntero en la mano enseñaba en un mapa una lección de geografía a sus alumnos. La puerta de la escuela estaba abierta; justo a su lado y sentado, con los chavales haciendo rueda, iba señalando los distintos países de Europa. Sin detenerme, lo miré muy bien. Él no apartó la mirada del mapa. No se percató, no, claro, de mí, ni de que alguien pasaba por delante de su puerta. Me acordé —cómo no iba a acordarme!— de mi propia escuela, de mis rapaces, de un mundo de afanes y empeños que quedaba tan cerca y tan lejos al mismo tiempo. ${ }^{100}$

\footnotetext{
${ }_{97}$ Calificativos que aparecen en un Informe emitido por el alcalde de Tomiño, Francisco Pino, a la Junta Provincial de Beneficencia, con fecha 4 de febrero de 1938. Archivo Histórico Provincial de la Diputación de Pontevedra. Sección Ensino Primario-Beneficencia, c. 19.254.

${ }_{98}$ Este periodo de su vida, conviviendo con su alter ego Afranio de Amaral quedó reflejado en un libro: O siñor Afranio. Ou como me rispéi das gadoupas da morte (Vigo: Edicións Castrelos, 1979) (1. ${ }^{\text {a }}$ edición), escrito en gallego, del que traducimos al castellano el título, El señor Afranio o como me libré de las garras de la muerte, y los párrafos transcritos que aparecen en las siguientes páginas. Existen posteriores ediciones, a cargo de la editorial A Nosa Terra (Vigo: Pontevedra), de 2006 y 2008.

99 Alonso Ríos, O siñor Afranio, 166.

100 Alonso Ríos, O siñor Afranio, 75. Victoriano Taibo García (Compostela, 1885-Vigo, 1966), maestro y escritor vinculado al movimiento galleguista, ejerció el magisterio en diversas localidades de Galicia, entre ellas Morgadáns, en tierras próximas a Portugal.
} 


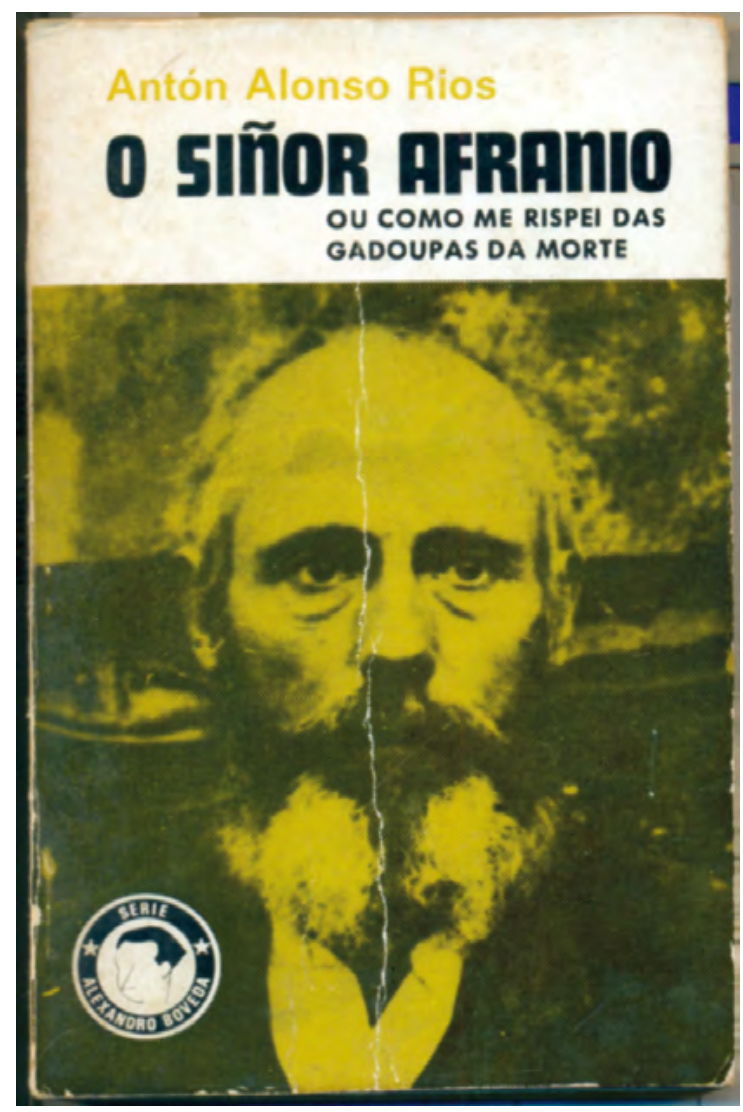

Imagen 7. Antón Alonso Ríos o Afranio de Amaral. Fotografía tomada en Ourense en 1939, todavía mendigo, que ha servido como portada para la primera edición (1979) del libro

Pocos días después le ocurrió lo mismo delante de la casa de Ramón Otero Pedrayo, ${ }^{101}$ y también pasó de largo, pues «bien comprendería que eso sólo serviría para crearle riesgos y hacer todavía más comprometida mi situación». ${ }^{102}$ Fueron tres años de incontables calamidades, —«en un

101 (Ourense, 1888-1976), intelectual y político, diputado por el PG en las Cortes Constituyentes republicanas. Miembro de la Xeración Nós y del Seminario de Estudos Galegos, Es autor de una amplia obra narrativa, ensayística y dramática. Sufrió la depuración del régimen franquista después del golpe de estado.

102 Transcribo la nota a pie de página: «En efecto, allí vivía entonces, retirado, desengañado y triste, don Ramón Otero Pedrayo, quien fuera diputado por el Partido Galeguista en las Cortes Constituyentes de la República. Aunque apartado de toda actividad política fue sancionado con la pérdida de su cátedra de Geografía e Historia en el Instituto de Ourense». Alonso Ríos, $O$ siñor Afranio, 98. 
campo sembrado de maíz cogí cuatro espigas, que metí en un talego hecho con el forro de la manga del abrigo. Solo cuatro, ya que, dado que comía una por día, más de cuatro días se ponían duras y no podía comerlas»—. ${ }^{103}$ Tres años recorriendo una parte de Galicia que ya había visitado anteriormente, en plena efervescencia republicana, celebrando mítines y reuniones vecinales en un clima de optimismo y esperanza y que ahora encontraba atenazada por noticias de guerra y represalia, traídas y llevadas por tabernas y caminos, y el terror a los fascistas:

El día 9 por la mañana, pasé junto a un calvario, y recordé el mitin que allí habíamos dado Paz Andrade, Bóveda y yo. Más adelante había una feria en la misma carretera. Mucha gente. A la derecha, un cuartel de falangistas con sus vestidos llamativos, los que yo veía por primera vez. No se fijaron en mí. Solo un pícaro de unos nueve o diez años, ya pasado el cuartel falangista, levantó la mano hacia mí y gritó: ¡Arriba España, arriba España! Como yo seguía caminando sin hacerle caso, el insistía enrabietado. Entonces, una buena mujer, con esa actitud de respeto tan propia de nuestras mujeres, reprendió al granuja: ¡Calla, rapaz. Respeta a las personas de edadi ¿No ves que puede ser tu padre o tu abuelo? ${ }^{104}$

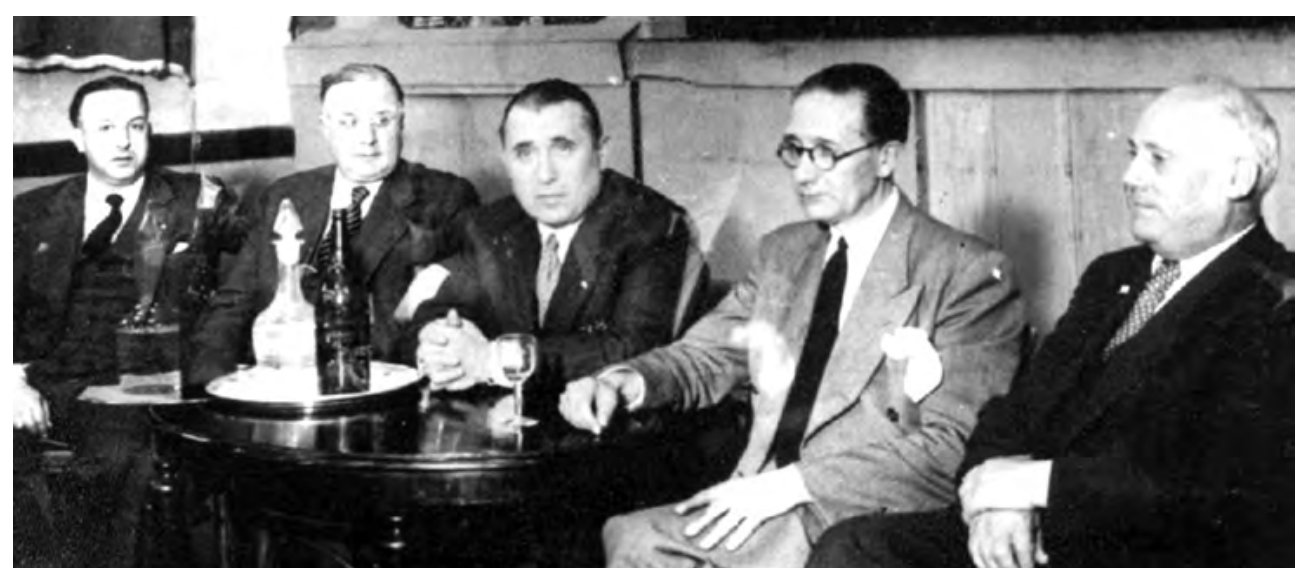

Imagen 8. Buenos Aires, años 40. Antón Alonso Ríos con Castelao, Secretario y Presidente (primero y segundo por la derecha respectivamente) del Consello de Galiza, gobierno gallego en el exilio, constituido en Montevideo en 1944

103 Alonso Ríos, O siñor Afranio, 65.

${ }^{104}$ Alonso Ríos, O siñor Afranio, 82. 
Una Galicia campesina paralizada por el pánico, donde la natural relación comunal entre vecinos se había contaminado, sembrando un clima de desconfianza que se fue extendiendo como una niebla densa y acabó ocupando todos los espacios de aquella sociedad rural indefensa e impotente:

En Filgueira me dieron una sardina en conserva en un negocio y pan de trigo en una casa. Tenía dudas de qué camino tomar. Al final me puse en marcha por la carretera de A Cañiza. Casi al salir de Filgueira, un falangista joven y muy garrido, alto, cuerpo de atleta muy bien formado y cara varonil me interrogó: qué estaba haciendo, de dónde era y demás. Y dándose por conforme con mis respuestas, estiró el brazo con la mano abierta y me ordenó que hiciera y repitiera lo que él hacía y decía: ¡Viva España! ¡Arriba España! ¡Abajo Rusia! Obedecí. Estiré el brazo y repetí sus palabras. Me despidió con un «vaya usted con Dios». Yo le respondí: «que lo guarde a usted». ${ }^{105}$

Fueron tres años de riesgos e incertidumbres que dan forma a una historia impresionante de exilio interior, recuperada muchos años después desde la distancia temporal y emocional. Tres años de convivencia estrecha con la muerte "pero también tres años de superación, de valor heroico, de victoria de la inteligencia». ${ }^{106}$ Y lo verdaderamente asombroso es comprobar cómo salió de la prueba «sin perder el sentido, manteniendo la mirada firme y la palabra sosegada», ${ }^{107}$ y sin un atisbo de resentimiento o de rencor hacia los verdugos.

Pero al cabo, Antón Alonso Ríos consigue cruzar a Portugal. En Lisboa encontró protección en la casa de su amigo Enrique Blanco, un tomiñés emigrante, de orientación republicana, hostelero de profesión. Muchos vecinos que huían de la represión utilizaban el restaurante Royal de Enrique Blanco como refugio para ocultarse y esperar allí prudentemente hasta poder partir hacia el exilio. ${ }^{108} \mathrm{En}$ su casa estuvo el

\footnotetext{
105 Alonso Ríos, O siñor Afranio, 89-90.

106 Álvarez Blázquez, «Prólogo», 24.

107 Álvarez Blázquez, «Prólogo», 25.

${ }^{108}$ El gesto de Blanco sería constantemente recordado y agradecido por el refugiado Alonso Ríos durante la fraternal relación que mantuvieron a lo largo del tiempo. Puede valer como ejemplo la
} 
tiempo necesario antes de pasar a Marruecos, donde conseguiría embarcar hacia la Argentina. El 13 de marzo de 1939 escribía a su amigo Blanco desde Casablanca — «Las cosas van muy bien, todavía mucho mejor de lo que yo esperaba. En el primer barco despacharé el encargo»-, revelándole en clave, para no comprometerlo, el anuncio de un pronto embarque. Aquí empezó su exilio exterior, rumbo a Buenos Aires, que duró hasta su muerte, en 1980.

\section{A MODO DE CONCLUSIÓN}

Antón Alonso Ríos fue una de las figuras centrales de la política gallega del primer tercio del siglo xx, dueño de una densa trayectoria que abarcó desde el trabajo como docente, tanto en la Argentina como en Galicia, hasta la acción política como diputado electo a las Cortes republicanas en 1936 representando al movimiento agrarista; además del periodismo y la literatura, mostrando en todas sus facetas «la terquedad dinámica; el estímulo; la piedra que no se deja arrancar, pero a veces se lanza con formidable ímpetu, y agita y estremece». ${ }^{109}$

Comenzando por la faceta política, fue el animador de un movimiento societario que se aglutinó alrededor de la Federación de Sociedades Gallegas, Agrarias y Culturales. Junto a Ramón Suárez Picallo y Eduardo Blanco Amor representó a la Federación de Sociedades, como delegado en Galicia entre 1931 y 1936, para la promoción del Estatuto de Autonomía. Durante ese tiempo participó en decenas de actos políticos por pueblos y villas gallegas — «un volcán de pasión cívica asemeja su verbo, que enardece a la multitud», ${ }^{110}$ se publicaba en el semanario Galicia de Buenos Aires con motivo de la celebración de un acto de la ORGA—. ${ }^{111}$ Fue proclamado Presidente de la Junta Revoluciona-

\footnotetext{
afectuosa dedicatoria en una fotografía que le envía algunos años después desde Buenos Aires, que nosotros traducimos: «Para el Hermano Enrique Blanco con un fuerte abrazo de su agradecido

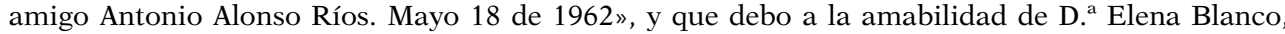
hija de Enrique Blanco.

109 «El jueves se celebró un gran acto de homenaje de simpatía a los delegados de la Federación», Galicia 209 (1931): 1

110 «Mitin de afirmación republicana organizado por la ORGA fue un acto grandioso y entusiasta», Galicia 185 (1930): 2.

${ }^{111}$ La Organización Republicana Gallega Autónoma (ORGA) fue un partido político gallego en la órbita de la izquierda, de orientación republicana, galleguista, autonomista. Fue fundado por San-
} 
ria de la República Gallega en junio de 1931, aunque sin consecuencias prácticas $^{112}$ y logró su acta de diputado en Madrid en 1936. Fue uno de los impulsores de las Mocidades Galeguistas y el secretario del Consello de Galicia —el gobierno gallego en el exilio-, desde su constitución en 1944. Tal era su modestia, que a la muerte de Alfonso D. Rodríguez Castelao, ${ }^{113}$ no quiso ocupar el lugar de un Presidente insustituible, y continuó como Secretario, en su ausencia, hasta la disolución del Consello. ${ }^{114}$

Indica Suárez Picallo que Alonso Ríos significó el alma, el nervio y el verbo de la Federación desde el día de su nacimiento. Miembro, en casi todos los períodos, de su Junta Ejecutiva, director de sus periódicos ( $E l$ Despertar Gallego y Galicia) y ponente en sus Congresos. Para Eduardo Blanco Amor fue «de los que día a día dieron a la organización federal todo lo que puede darse: ideas, pesos, trabajo personal y ejemplo de entereza y austeridad». ${ }^{115}$ Para los coterráneos emigrantes fue el «maestro y guía austero de la juventud gallega y de los hombres que ansían la redención de la patria». ${ }^{116}$ Para Castelao, su hermano en la política y más tarde en el exilio fue «el hombre llamado a despertar y dignificar el agrarismo, levantando las sociedades agrarias de la situación enervada y decaída en que adormecían». ${ }^{117}$

tiago Casares Quiroga y Antonio Vilar Ponte en octubre de 1929 en A Coruña con la participación de las Irmandades da Fala. Véase: José Luis de la Granja, Justo Beramendi y Pere Anguera, La España de los nacionalismos y las autonomías (Madrid: Síntesis, 2003).

112 «Alonso Ríos es nombrado Presidente de la Junta Revolucionaria de la República Gallega», El Pueblo Gallego 2256 (1931): 4.

${ }^{113}$ Alfonso Daniel Rodríguez Castelao es un referente político y moral del nacionalismo gallego, además de intelectual y artista, en cuya obra literaria y pictórica reflejó un hondo compromiso con Galicia. Fue Presidente del Consello de Galiza en el exilio argentino, hasta su muerte en 1950. Sus restos, traídos a Galicia en 1984, descansan en el Pabellón de Gallegos Ilustres, en Santiago de Compostela, junto a los poetas Rosalía de Castro y Ramón Cabanillas, el político regionalista Alfredo Brañas, el escultor Francisco Asorey y el geógrafo Domingo Fontán. En 1964, la Real Academia Gallega le dedicó el Día das Letras Galegas. Más información en el perfil: https://academia.gal/ figuras-homenaxeadas/-/journal_content/56_INSTANCE_8klA/10157/28701. Consultado 19/04/2018.

${ }^{114}$ El denominado Consello de Galiza nació en Montevideo en 1944 como un órgano político para visibilizar el gobierno de Galicia en el exilio, que ya había sido legitimado por el Estatuto de Autonomía, aprobado en plebiscito en 1936. Castelao fue su Presidente y Antón Alonso Ríos su secretario hasta su disolución.

115 Eduardo Blanco Amor, «Antonio Alonso Ríos y la juventud gallega», El Despertar Gallego 95 (1927): 1 .

116 «El homenaje popular a Alonso Ríos», El Despertar Gallego 94 (1927): 4.

${ }_{117}$ Castelao escribe el prólogo de su libro Co pensamento na patria galega, que Álvarez Blázquez incluye como apéndice en la edición de O Siñor AFranio. De ahí extraemos este comentario (p. 207). 
La actividad periodística ocupó, asimismo, una parte importante de su faceta pública. Fue director de El Despertar Gallego, órgano oficial de la Federación de Sociedades, donde publicó numerosos artículos de temática política, agrarista y pedagógica. También colaboró en Galicia continuación de El Despertar Gallego en el que firmó con nombre propio y también probablemente con el seudónimo Antonio D'Amarante-, además de en Céltiga, La Zarpa, El Orensano o El Pueblo Gallego. Y en el conjunto de su abundante producción periodística mostró «la terquedad dinámica; el estímulo; la piedra que no se deja arrancar, pero a veces se lanza con formidable ímpetu, y agita y estremece». ${ }^{118}$ Son palabras de despedida en un homenaje que le dedicaron sus compañeros de la Federación de Sociedades en Buenos Aires, en 1931, poco antes de embarcar para Galicia.

Su producción escrita no se limitó a la actividad periodística. Es autor de varias novelas y ensayos publicados después de su regreso a Sudamérica, a partir de $1940 .{ }^{119}$ Con respecto al trabajo pedagógico, funde rasgos del modelo institucionista con la práctica docente en la Argentina y la dirección de la «Aurora del Porvenir». Los principios básicos de su discurso reivindican una escuela gallega partiendo de la renovación de todos sus aspectos: concepción, métodos, infraestructura, profesorado, organización..., y se concretan en una serie de propuestas que recogió del sistema público argentino y modeló para adaptar a la realidad gallega.

Alonso Ríos mantuvo durante tres décadas — desde la llegada a Compostela como estudiante de Magisterio y la retirada forzosa por los montes de Tebra, víctima de la represión fascista- una intensa actividad, centrada en su única obsesión: la emancipación de las clases populares gallegas. En 1935 escribía lo siguiente, con lúcida premonición:

De la escuela campesina y del campo, de esta fuente inagotable de humanidad y de riqueza, es de donde hay que esperarlo todo. Pero no huyendo a las ciudades para extraer desde la co-

\footnotetext{
118 «El jueves se celebró un gran acto», 1.

119 Co pensamento na Patria galega: diante dunha nova xeira (Buenos Aires: Editorial Suevia, 1942); Noite i Amañecer de Galiza (Buenos Aires: Irmandade Galega, 1942); Da saudade: amore, arte e misticismo (Buenos Aires: Artes gráficas Alonso Ruiz, 1956); A cultura galega na súa dimensión americán. Bases pra unha política galega e peninsuare (Buenos Aires: Editorial Prisciliano, 1961); Nidia (Sada-A Coruña: Ediciós do Castro, 1992). O Siñor Afranio; y el estudio matemático Tratado da Velocidade (manuscrito) donde plasma sus teorías sobre esta materia.
} 
modidad y esterilidad burocráticas los menguados frutos que el campesino desamparado y depauperado arranca a la tierra. Hay que ir al campo con generoso espíritu de cooperación, con el ánimo dispuesto a aceptar cordialmente las solicitaciones del medio. Hay que ir al campo dispuestos a darse, no sólo a recibir sus caricias y sus frutos. Hay que ir al campo, pero despojado de la carroña señoritil que embota la sensibilidad, inhibe la acción y castra la iniciativa. Hay que ir al campo sintiéndose hombres, con corazón para amarlo y con potencialidad genésica para fecundarlo. Y si no vamos al campo, él vendrá a nosotros en inmensa ola burocrática y soldadesca, en avalancha obrera y en masa de parados. Y entonces ya no será necesaria la escuela campesina, al menos por un gran rato. ${ }^{120}$

A pesar de su formación y experiencia, de la intensa actividad social y de su reconocimiento público, Alonso Ríos fue, para los que le conocieron, un hombre sobrio y modesto que nunca hizo ostentación de su sólida formación.

Durante los últimos años, continuó participando en la vida de la colectividad sin que para ello le afectaran los límites de su precaria situación personal. Pero, a pesar de su entregada labor entre la comunidad gallega emigrada desde la llegada a Buenos Aires y hasta 1931; a pesar de su responsabilidad en la política gallega, orientada a la noble defensa de los intereses de las clases populares, entre 1931 y 1936; a pesar de la criminal persecución que padeció desde el golpe de estado; a pesar de la relevancia en su puesto, al frente del Gobierno gallego en el exilio al lado de Castelao, a partir de 1944; y a pesar de la postura firme, del ejemplo constante, de la entrega incondicional durante todo su tiempo de emigración, de república, de exilio, después de ser encaminado el nuevo Estatuto, en 1980, Antón Alonso Ríos comprobó con una profunda tristeza que en aquella Galicia tantos años esperada, nadie contaba con él para iniciar un tiempo ilusionante, ya sin dictador. Un olvido ingrato, que no habían tenido con sus exiliados las instituciones recién formadas de las otras dos comunidades autónomas históri-

\footnotetext{
${ }^{120}$ Antón Alonso Ríos, "Sobre lo que puede ser la nueva escuela rural gallega», El Pueblo Gallego 3530 (1935): 1 .
} 
cas. Y fue en esa injusta soledad donde decidió poner fin a su vida sin ver cumplido el deseo de regresar a Galicia y terminar su «longa noite de pedra». ${ }^{121}$ Con su muerte desapareció una de las máximas figuras representativas del compromiso político de los gallegos y gallegas emigrados, aquel puñado de personas generosas que un día soñaron con crear una Galicia moderna, auténticamente democrática y republicana.

\section{Nota sobre el autor}

Xosé M. Malheiro Gutiérrez (Moxico, Angola, 1961) es Doctor en Filosofía y Ciencias de la Educación por la Universidad de Santiago de Compostela y Profesor Contratado Doctor en el Dpto. de Pedagoxía e Didáctica de la Facultad de Ciencias de la Educación de la Universidade da Coruña. Anteriormente lo fue en la de Vigo (2001-2002) y la de Santiago (20032008). Ha publicado diferentes trabajos sobre la intervención educativa de la emigración gallega a América y ha ganado varios premios relacionados con la investigación histórico-educativa. Es miembro de los grupos de investigación ESCULCA (USC) y Política educativa, Historia e Sociedade (UDC). Pertenece a la SEDHE y es miembro del movimiento de renovación pedagógica Nova Escola Galega. Investiga sobre los procesos migratorios y sus implicaciones en la escuela; el contenido de los manuales escolares; y el empleo de la fotografía y el cine como recursos para el estudio de la memoria escolar.

\section{REFERENCIAS}

Alonso Fernández, Bieito. Antón Alonso Ríos: Crónica dunha fidelidade. Santiago de Compostela: Edicións Laiovento, 1996.

Álvarez Blázquez, Xosé María. «Prólogo». En O Siñor Afranio. Ou como me rispei das gadoupas da morte, editado por Antón Alonso Ríos, 7-26. Vigo: Edicións Castrelos, 1979.

\footnotetext{
121 «Longa noite de pedra» es el título del poema de Celso Emilio Ferreiro (1912-1979), poeta y escritor gallego antifranquista. Forma parte del libro homónimo, ejemplo de la poesía social de posguerra que alude metafóricamente al tiempo que duró, y fue soportada por una parte de la población, la dictadura del general Franco y refleja la miseria de las clases trabajadoras, la emigración, la opresión política, el ansia de libertad y el antibelicismo. Longa Noite de Pedra (Vigo: Edicións Xerais de Galicia, 1962. 1. ${ }^{\text {a }}$ edición).
} 
Armesto Victoria. Los Hijos cautivos de Breogán. El rastro de Castelao en América. Sada-A Coruña: Ediciós do Castro, 1986.

Barausse, Alberto. «Nationalisms and schooling: between italianity and brazility, disputes in the education of italian-gaucho people (Rs, Brazil, 1930-1945)». History of Education \& Children's Literature XII, no. 2 (2017): 443-475.

Cid Fernández, Xosé Manuel. Educación e ideoloxía en Ourense na II República. Organización e acción socioeducativa do maxisterio primario. Santiago: Andavira, 2010.

Cocho de Juan, Federico. Guerra Civil. Que pasou en Galicia e en España. Vigo: Edicións Xerais de Galicia, 2011.

Costa Rico, Antón. Escolas e Mestres. A educación en Galicia: da Restauración á II. ${ }^{a}$ República. Santiago de Compostela: Xunta de Galicia, 1989.

Costa Rico, Antón. A Colonia Escolar Compostelana de 1893. Primeiro Centenario. Santiago de Compostela: Consorcio de Santiago, 1993.

Costa Rico, Antón. «Emigrantes, escuelas y regeneración social: los emigrantes gallegos a América y el impulso de la educación (1879-1936)». Revista Brasileira da Educaçao 16 (2008): 13-44.

Costa Rico, Antón. «Os ensinantes galegos e o 36. Os mortos e os exiliados». En A II. ${ }^{a}$ República e a Guerra Civil, editado por VV.AA., 487-521. A Coruña: Deputación de A Coruña, 2006.

Costa Rico, Antón y Xosé Manuel Malheiro Gutiérrez. «La investigación histórico-educativa en Galicia, 2002-2014». Historia y Memoria de la educación 4 (2016): 307-335.

Díaz, Hernán M. Historia de la Federación de Sociedades Gallegas. Buenos Aires: Fundación Sotelo Blanco-Biblos, 2007.

Fariña Jamardo, Xosé. La parroquia rural en Galicia. Madrid: Instituto de Estudios de Administración Local, 1975.

Fernandes Alves, Jorge. «Percursos de um brasileiro no Porto: o Conde de Ferreira». Revista da Faculdade de Letras. História 9 (1992): 199-214.

Fernandes Alves, Jorge. "Os Brasileiros»: Emigração e Retorno no Porto Oitocentista. Porto: Faculdade de Letras da UP, 1993.

Fernández Prieto Lourenzo y Miguel Cabo Villaverde. «Agrarismo y regeneracionismo en la Galicia de comienzos del siglo xx: El desarrollo del regionalismo agrícola». Agricultura y sociedad 86 (1998): 133-162.

Ferreiro, Celso E. Longa Noite de Pedra. Vigo: Edicións Xerais de Galicia, 1962 (1. a edición).

Godio, Julio. El nacimiento de la clase obrera argentina. Buenos Aires: Editorial Legasa, 1987.

Gabriel, Narciso de. «Emigración y alfabetización en Galicia». Historia de la educación. Revista interuniversitaria 4 (1985): 321-336. 
Gabriel, Narciso de. «A emigración como factor dinamizador da alfabetización». En Actas do Congreso Emigración e Educación (1900-1936). I Centenario das Escolas da Unión Hispano-Americana Valle Miñor (1909-2009), coordinado por Xosé Manuel Malheiro Gutiérrez, 205-27. Gondomar: Instituto de Estudos Miñoranos/Consello da Cultura Galega, 2011.

Gabriel, Narciso de. "Arximiro Rico: vida e morte dun mestre republicano». Sarmiento. Anuario Galego de Historia da Educación 4 (2000): 9-38.

Gabriel, Narciso de. «Republicanismo e educación». En El republicanismo coruñés en la historia, 257-266. A Coruña: Concello da Coruña, 2001.

Garazo, Antón. «Silleda e a comarca de Deza: políticos de onte e políticos de hoxe». A Trabe de ouro. Publicación galega de pensamento crítico 9 (1992): 35-46.

Granja, José Luis de la, Justo Beramendi, Pere Anguera. La España de los nacionalismos y las autonomías. Madrid: Síntesis, 2003.

Gurriarán, Ricardo. Ciencia e conciencia na Universidade de Santiago (19001940). Santiago de Compostela: Servizo de Publicacións da Universidade, 2006.

Malheiro Gutiérrez, Xosé Manuel. "Antón Alonso Ríos: política e pedagoxía para un pobo». En VV. AA., Homenaxe a Antón Alonso Ríos e Ramón de Valenzuela, 101-110. Santiago de Compostela: Xunta de Galicia, 2006.

Malheiro Gutiérrez, Xosé Manuel. «Antón Alonso Ríos: unhas notas sobre emigración, agrarismo e vida rural». A Trabe de Ouro. Publicación galega de pensamento crítico 53 (2003): 81-85.

Malheiro Gutiérrez, Xosé Manuel. "Do "gobernar es poblar" ao "educar es argentinizar": Emigrantes e educación na Arxentina finisecular». Sarmiento. Anuario Galego de Historia da Educación 17 (2013): 161-184.

Malheiro Gutiérrez, Xosé Manuel. Herdanza da emigración ultramarina. Pontevedra: Deputación de Pontevedra, 2005.

Malheiro Gutiérrez, Xosé Manuel. As escolas dos emigrantes e o pensamento pedagóxico: Ignacio Ares de Parga e Antón Alonso Ríos. Sada-A Coruña: Ediciós do Castro. 2006.

Malheiro Gutiérrez, Xosé Manuel. «Una nueva luz. La influencia de la escuela argentina en la intervención de los emigrantes gallegos en sus lugares de origen». Historia de la Educación. Revista interuniversitaria 26 (2007): 341-66.

Mato, Alfonso. O Seminario de Estudos Galegos. Sada-A Coruña: Ediciós do Castro, 2001.

Morente Valero, Francisco. La escuela y el Estado Nuevo. La depuración del Magisterio Nacional (1936-1943). Valladolid: Ámbito Ediciones, 1997.

Morente Valero, Francisco. «La muerte de una ilusión: el Magisterio español en la Guerra Civil y el primer franquismo». Historia y Comunicación social 6 (2001): 187-201. 
Núñez Seixas, Xosé Manoel. O galeguismo en América, 1879-1936. Sada-A Coruña: Ediciós do Castro, 1992.

Núñez Seixas, Xosé Manoel. Emigrantes, caciques e indianos: o influxo sociopolítico da emigración transoceánica en Galicia (1900-1930). Vigo: Edicións Xerais de Galicia, 1998.

Nuñez Seixas, Xosé Manoel. «A parroquia de Alén Mar: Algunhas notas sobre o asociacionismo local galego en Buenos Aires (1904-1936)». Semata. Ciencias Sociais e Humanidades 11 (1999): 345-379.

Nuñez Seixas, Xosé Manuel. O inmigrante imaxinario. Estereotipos, representacións e identidades dos galegos na Arxentina (1880-1940). Santiago de Compostela: Universidade de Santiago de Compostela, 2002.

Oved, Iaacov. El anarquismo y el movimiento obrero en Argentina. Buenos Aires: Siglo XXI, 1978.

Peña Saavedra, Vicente. «Panorámica de la intervención escolar de los emigrantes gallegos a América (siglos XVII-XXI)». En El asociacionismo y la promoción escolar de los emigrantes del Norte Peninsular a América, coordinado por Moisés Llordén Miñambres y José Manuel Prieto Fernández del Viso, 35-69. Boal: Ayuntamiento de Boal, 2012.

Porto Ucha, Ánxo. Mestras e mestres pontevedreses depurados polo franquismo. Primeiras accións represivas e estudo por concellos no sur da provincia (1936-1942). Ponteareas: Alén Miño, 2008.

Puigróss, Adriana. Sujetos, disciplina y curriculum en los orígenes del sistema educativo argentino (1885-1916). Buenos Aires: Editorial Galerna, 2006.

Rivas Barrós, Sabela. A derradeira lección dos mestres. Galeguismo e pensamento pedagóxico (1900-1936). Vigo: Edicións Xerais de Galicia, 2001.

Sardi, Valeria. Historia de la enseñanza de la lengua y la literatura. Continuidades y rupturas. Buenos Aires: Libros del Zorzal, 2006.

Souto Blanco, María José. La represión franquista en la provincia de Lugo (1936-1940). Sada-A Coruña: Ediciós do Castro, 1998.

Souto Blanco, María José. Anos de odio. Golpe, represión e Guerra Civil na provincia da Coruña (1936-1939). A Coruña: Deputación da Coruña, 2007.

Valcárcel, Marcos. «Galicia en la 2. ${ }^{a}$ República: El Estatuto de Autonomía». En Historia de Galicia. La época contemporánea, 933-952. Vigo: Faro de Vigo/ Caixavigo, 1991, 933. Tomo IV.

Valín Fernández, Alberto. Laicismo, educación y represión en la España del siglo XX. Orense, 1909-1936/39. Sada-A Coruña: Ediciós do Castro, 1993.

Vilanova Rodríguez, Alberto. Los gallegos en la Argentina. Buenos Aires: Ediciones Galicia, 1966. 2 vols.

Viñao Frago, Antonio. "Filantropía y educación. Fundaciones docentes y enseñanza elemental (siglos XVIII-XIX)». En L'enseignement primaire en Espagne 
et en Amérique Latine du XVIII siècle à nos jours, dirigido por Jean-René Aymes, Ėve-Marie Fell y Jean-Louis Guereña, 65-79. Tours: Université de Tours, 1986.

Viñao Frago, Antonio. «Memoria escolar y guerra civil. Autobiografías, memorias y diarios de maestros y maestras». Cultura Escrita \& Sociedad 4 (2007): 171-202. 